\title{
Actitudes, consumo de agua y sistema de tarifas del servicio de abastecimiento de agua potable
}

\author{
Cruz García Lirios \\ Universidad Nacional Autónoma de México (ENTS-Facultad de Psicología), México, \\ México. Email: garcialirios@gmail.com \\ Javier Carreón Guillén \\ Universidad Nacional Autónoma de México (ENTS-Facultad de Psicología), México, \\ México. Email: javierg@unam.mx
}

\section{Jorge Hernández Valdés}

Universidad Nacional Autónoma de México (ENTS-Facultad de Psicología), México, México. Email: jorheval@unam.mx

\section{María Montero López Lena}

Universidad Nacional Autónoma de México (ENTS-Facultad de Psicología), México, México. Email: monterol@unam.mx

\section{José Marcos Bustos Aguayo}

Universidad Nacional Autónoma de México (ENTS-Facultad de Psicología), México, México. Email: marcos.bustos@unam.mx

Resumen: La Psicología de la Sustentabilidad (PS) estudia las problemáticas hídricas considerando la relación entre disponibilidad per cápita y consumo de agua. A partir de conceptos tales como; densidad poblacional, infraestructura hídrica y provisión de agua plantea tres estilos de vida relativos al almacenamiento de agua, la reparación de fugas y el consumo hídrico. La PS advierte que las relaciones causales entre las problemáticas hídricas y los estilos de vida son relevantes si se considera el Desarrollo Local Sustentable más que regional y global. A medida que las problemáticas hídricas se intensifican, procesos actitudinales y de austeridad prevalecen sobre el dispendio de agua. En contraste, las situaciones hídricas en equilibrio con el consumo residencial facilitan el dispendio. La discusión alusiva a las problemáticas hídricas y los estilos de vida permitirá construir un sistema tarifario de consumo y delimitar las políticas públicas que se requerirán en el marco de la crisis de abastecimiento y distribución que se espera en los próximos años.

Palabras clave: Densidad, Infraestructura, Provisión, Almacenamiento, Reparación y Consumo. 


\title{
Attitudes, and water consumption system service fees water sufficiency
}

\begin{abstract}
The Psychology of Sustainability (PS) studies the issues involving the relationship between water availability per capita and water consumption. From concepts such as: population density, water infrastructure and water provision raises three lifestyles concerning water storage, leak repairing and water consumption. The PS notes that the causal relationships between water issues and lifestyles are important if one considers Local Sustainable Development rather than regional and global. As water problems intensify, attitudinal processes of austerity prevail over the waste of water. In contrast, water situations in equilibrium with residential consumption facilitate wastefulness. The discussion alluding to water problems and lifestyles will allow to build a rate system for consumption and define the policies that will be required in a context of supply and distribution crisis expected in the coming years.
\end{abstract}

Key words: Density, Infrastructure, Provision, Storage, Repair and Consumption

\section{Atitudes, consumo de água e sistema de tarifas do serviço de abastecimento de água}

Resumo: A Psicologia da Sustentabilidade (PS) examina as questões que envolvem a relação entre a disponibilidade de água per capita e consumo de água. A partir de conceitos, tais como: densidade populacional, a oferta de infra-estrutura de água e água coloca três estilos de vida para o armazenamento do consumo de reparação de água, vazamento e água. A PS observou que as relações causais entre as questões da água e estilos de vida são relevantes quando se considera o desenvolvimento sustentável local e regional e não global. Como as questões se intensifica, os processos comportamentais e austeridade prevalecer sobre o desperdício de água. Em contraste, a água em situações de equilíbrio com o consumo residencial facilitar o desperdício. A discussão aludindo às questões da água e estilos de vida irá construir um sistema tarifário do consumidor e definir as políticas que serão necessárias no contexto da oferta global e distribuição está prevista para os próximos anos.

Palavras-chave: Densidade, Infra-estrutura, suprimento, armazenamento, Reparação e do Consumidor

La relación entre la naturaleza y la humanidad tiene como punto de enlace la disponibilidad de recursos y su distribución equitativa entre las especies animales y vegetales, incluidas las humanas, actuales y futuras. En torno al Desarrollo Sustentable, el agua es considerada por los científicos sociales como un recursos cuya disponibilidad y distribución impactará significativamente los usos y costumbres humanos en su vida cotidiana, familiar, laboral o escolar.

A lo largo de sus ciclos, los recursos naturales presentan variaciones en sus niveles de disponibilidad afectando su redistribución en las especies y determinando su subsistencia. Si la variación "natural” o "cíclica” de los 
recursos naturales es moderada por las necesidades, expectativas o costumbres de una parte de la humanidad que consumió, en su gran mayoría, los recursos naturales a partir de la revolución industrial, entonces la escasez de recursos puede ser considerada como un efecto del crecimiento económico que permitió el consumo excesivo de recursos sin considerar la subsistencia de las especies futuras.

Sin embargo, una gran parte de la humanidad, marginada y excluida del consumismo de recursos naturales, se adaptó a la inequidad distributiva construyendo estilos de vida austeros, altruistas o contraculturales. En este sentido, las variaciones de disponibilidad de los recursos naturales parecen haber sido la causa principal de la adopción de estilos de vida favorables a su preservación con la intención de garantizar la subsistencia de las generaciones excluidas del futuro.

Las variaciones de los recursos hidrológicos, tienden a configurar tres problemáticas relativas a la densidad poblacional y el volumen de almacenamiento, la infraestructura del servicio público y las iniciativas domésticas de mantenimiento de la red pública y domiciliaria, el volumen de provisión y el consumo doméstico.

En el presente ensayo, podrán apreciarse éstas tres relaciones en el ámbito de la Ciudad de México cuya complejidad, ejemplifica la tendencia de las políticas públicas en torno al servicio público de agua potable y las características sociodemográficas de sus habitantes en las que sus variaciones permitirán sistematizar y predecir la exclusión social que impedirá la sustentabilidad hídrica de la megalópolis. Para tal propósito es menester considerar que las ciencias sociales han abordado las problemáticas descritas a partir de sus áreas de especialización en las que la unidad de análisis es el individuo, el grupo, el barrio, la comunidad, la organización, la urbe, la población, el Estado, la cultura o la generación en referencia a la escasez de agua, la calidad del servicio, el nivel de mantenimiento y la política pública.

En el presente trabajo, se analiza la tendencia de crecimiento y densidad poblacional en relación directa con sus hábitos de almacenamiento prevalecientes. Se observa que un incremento en la tendencia poblacional implica un aumento indiscriminado de almacenamiento de agua. Esta relación agrava la situación de exclusión y marginalidad en la que se encuentran los habitantes que históricamente han lidiado con la escasez o abasto irregular de agua. Se trata de una exclusión hídrica de segundo orden puesto que quienes pagan menos por el servicio público consumen cada vez más y quienes pagan más consumen cada vez menos, se genera una competencia por el almacenamiento de agua entre quienes ya son considerados marginados o incluso, excluidos.

En el presente ensayo también se analiza la relación entre la infraestructura de la red pública y las iniciativas de reparación generadas por la autogestión o autorganización de las comunidades y los barrios periféricos 
que viven cotidianamente el derroche de agua causado por fugas. Las ciencias sociales se han avocado a describir ésta relación que en el caso de la Ciudad de México, subyace como resultado de las políticas públicas deficientes en la atención a la problemática de escasez y fugas colaterales del servicio público.

Finalmente, se aborda la relación entre el abasto irregular de agua y la dosificación de su consumo. Quizá, ésta sea la principal respuesta de las zonas excluidas o marginadas del servicio público puesto que el almacenamiento y la reparación de fugas no siempre resultan eficaces, el ahorro de agua es la principal estrategia de subsistencia entre los habitantes que sufren la exclusión hídrica de segundo orden.

El lector advertirá la ausencia de un marco teórico que explique las relaciones entre las problemáticas y los estilos de vida. Sin embargo, el objetivo del presente documento es sistematizar los indicadores de las relaciones descritas para construir instrumentos de medición que permitan demostrar algunas hipótesis relativas a la disponibilidad y redistribución de agua entre los habitantes y los estilos de vida subyacentes.

El objetivo del presente ensayo es establecer la conceptuación de las actitudes hacia la sustentabilidad en torno al consumo de agua. Para tal propósito, se revisan la Teoría de la Disonancia Cognitiva, la Teoría de la Acción Razonada, la Teoría del Comportamiento Planificado, la Teoría de la Probabilidad de Elaboración y la Teoría del Procesamiento Improvisado para explicar el dispendio o ahorro de agua a partir de su disponibilidad tipificada como escasa o abundante, sus creencias antropocéntricas o ecocéntricas y sus actitudes favorables o desfavorables. La comparación entre las cinco teorías permitió conceptualizar la formación y función de las actitudes hacia la sustentabilidad hídrica.

\section{Situación hidrológica mundial}

La problemática del agua en el mundo esta interconectada climática y económicamente. El $97.5 \%$ es salada, 2.24\% es dulce y solo 1\% esta disponible en ríos, lagos y acuíferos para el consumo humano. $113000 \mathrm{~km}^{3}$ de agua, se precipitan anualmente. En el mundo, $7100 \mathrm{~km}^{3}$ se evapora, $42000 \mathrm{~km}^{3}$ regresa a los océanos y se filtra a los acuíferos. Anualmente, el $70 \%$ entre 9000 y $14000 \mathrm{~km}^{3}$ mantienen los ecosistemas y sólo 4200 km (30\%) está disponible para irrigación, industria (23\%) y uso domestico (8\%). Se estima que en el 2025 el 80\% de la población mundial estará en alta escasez. La Organización de Naciones Unidas (ONU) en su informe correspondiente al 2005 señala que 23,8 millones de $\mathrm{km}^{3}$ de agua se encuentra congelada, $74200 \mathrm{~km}^{3}$ se evapora, $119000 \mathrm{~km}^{3}$ se precipita en los continentes, $458000 \mathrm{~km}^{3}$ se precipita en el mar, $502800 \mathrm{~km}^{3}$ se evaporan de los océanos, 10,4 millones de $\mathrm{Km}^{3}$ están depositados en acuíferos, 900900 km³ se encuentran disponible en lagos, 1.350 millones están depositados en los océanos. Anualmente, en los océanos (que contienen 1350 millones de km³), 
el ciclo hidrológico implica la evaporación de $502800 \mathrm{~km}^{3}$ de agua de los cuales $458000 \mathrm{~km}^{3}$ regresan en precipitaciones, $42600 \mathrm{~km}^{3}$ regresan en derrames superficiales y $2200 \mathrm{~km}^{3}$ en derrames subterráneos. En los continentes (que contienen $23800000 \mathrm{~km}^{3}$ de agua en hielo y nieve, 10400000 $\mathrm{km}^{3}$ en acuíferos y 901000 en lagos y ríos), $119000 \mathrm{~km}^{3}$ de agua se precipitan y $74200 \mathrm{~km}^{3}$ se evaporan al año. La ONU (2005) pronostica para el año 2050 un rango de aumento de la temperatura de 1,4 a 5,6 centígrados causando un incremento de 44 centímetros del nivel del mar, un 5\% más de las precipitaciones y la extinción de una cuarta parte de las especies (véase gráfico 1).

\section{Gráfico 1. Situación Hidrológica Global}

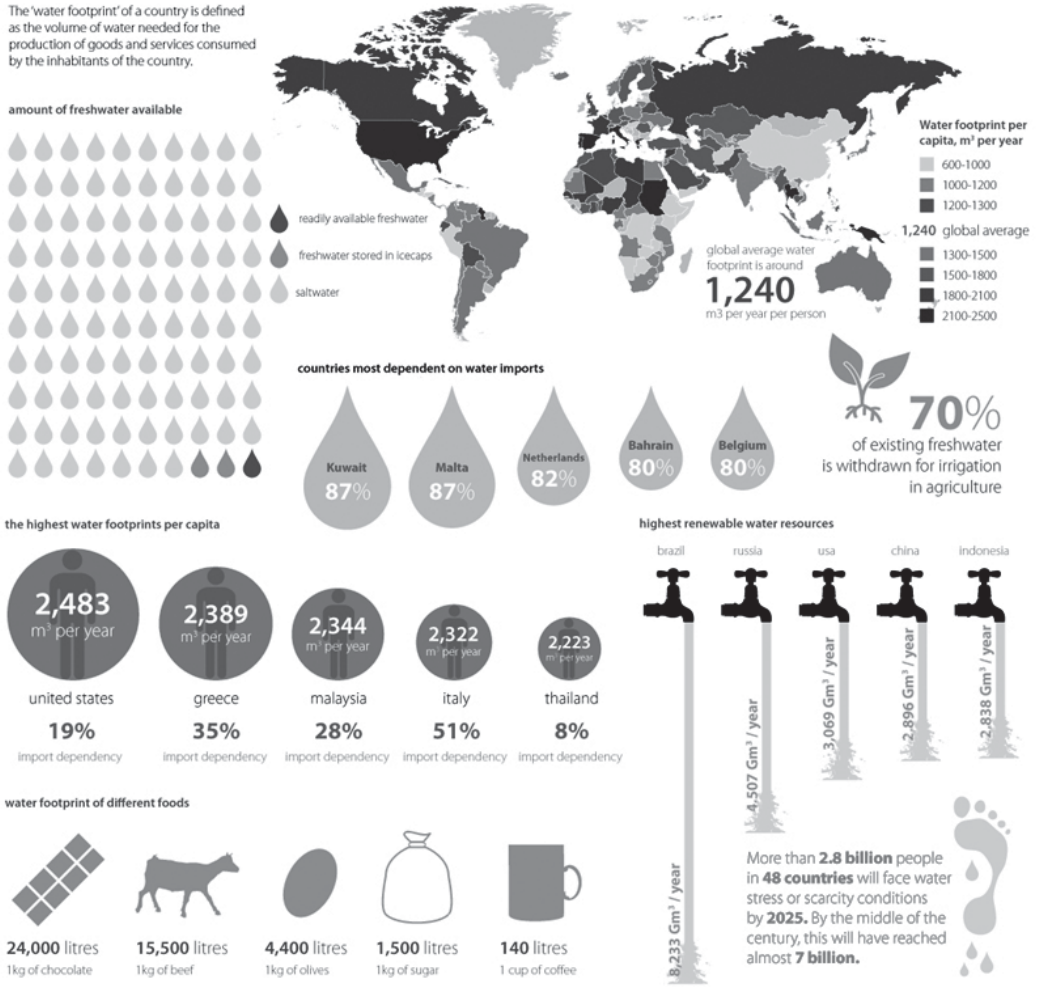

Fuente: Aquastat (2010)

Los flujos hidrológicos son cada vez más insostenibles. La disponibilidad del recurso ha disminuido paulatinamente. En 1950 sólo el conti- 
nente asiático tenía una baja disponibilidad y para el año 2025 esta escasez se extenderá a los cinco continentes. El desequilibrio entre la explotación (se estiman $4600 \mathrm{~km}^{3}$ ) del recurso y su recarga natural afectará su disponibilidad para el consumo (2400 km³ aproximadamente) en la agricultura, la industria y las actividades domesticas. En el mundo las principales problemáticas en torno al recurso agua son su abasto irregular e insalubre. Se estima que una quinta parte de la población mundial sufre escasez del vital líquido y que cinco millones de personas mueren cada año por beber agua contaminada. En este sentido, se estima para el año 2025 una crisis mundial de abasto irregular e insalubre de agua en la que 2000 millones de individuos no dispondrán de agua bebible (OMS, 2010).

\section{Situación hidrológica nacional}

México es el onceavo país con más población (101,7 millones de personas), con una densidad de 52 personas por $\mathrm{km}^{2}$ en promedio, una población menor de 15 años que es el 33\% la cual contrasta con el 5\% que son mayores de 60 años, el 74\% vive en zonas urbanas y su ingreso per cápita al año es de 8,790 dólares norteamericanos trabajando 40 horas a la semana. Además, su población crece anualmente a un ritmo de 2,1 millones y se espera que en el 2050 aumente 48\%, estimando su población para el 2030 de 131,7 (INEGI, 2010)

El 27.7 de la población infantil mexicana es extremadamente pobre y está concentrada en 4 millones en el Estado de México los cuales contrastan con los 8 millones de personas entre 15 y 64 años. Ambos grupos coexisten en la zona con mayor densidad poblacional aproximada de 12472 648 de habitantes (UNICEF, 2010).

\section{Gráfico 2. Situación hidrológica nacional}

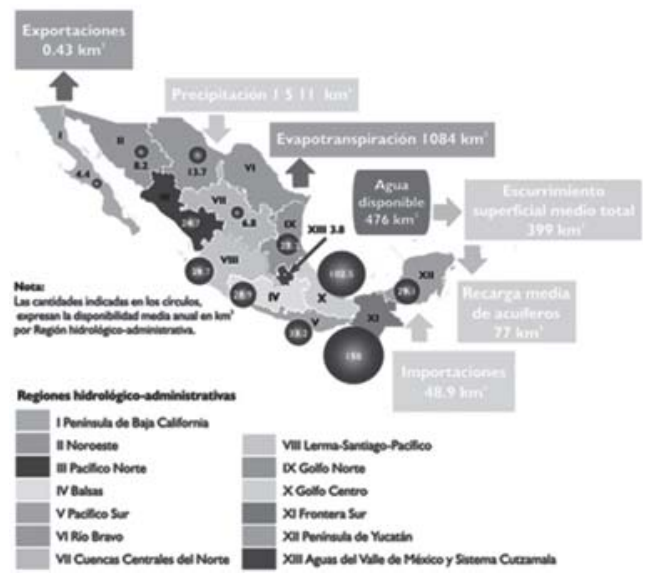

Fuente: Conagua (2010) 
La CONAGUA (2010) señala que más de 11 kilómetros cúbicos anuales han sido concesionados en la zona del centro occidente; el 53\% se extrae de acuíferos y el 47\% de lagos, ríos y manantiales. El 82\% está destinado a la agricultura, el 15\% al abastecimiento público y el 3\% a la industria (FAO, 2010).

La zona de mayor industrialización y comercio ha sido clasificada con un índice de disponibilidad extremadamente baja con menos de 1000 metros cúbicos por habitante al año(véase gráfico 2).

Respecto a las zonas centro y norte del país donde el crecimiento económico es significativo, la disponibilidad del recurso está clasificada como muy baja con 1000 a 2000 metros cúbicos por habitante al año. Sólo el sureste de México que ha tenido un crecimiento económico poco significativo, ha sido clasificado con una alta disponibilidad de 10000 metros cúbicos por persona al año. Las zonas norte, centro y noreste que contribuyen con el 85\% del Producto Interno Bruto (PIB) y tienen el 77\% de la población sólo cuentan con el 32\% de la disponibilidad de agua, aproximadamente 1874 metros cúbicos por habitante al año. En contraste, la zona sureste que contribuye con 15\% del PIB y concentra el 23\% de la población, tiene una alta disponibilidad del 66\% de los recursos hidrológicos, aproximadamente 13759 metros cúbicos por persona anuales. De este modo, el promedio de disponibilidad de agua nacional es de 4573 metros cúbicos por individuo al año. Se estima que el $28 \%$ del agua disponible es consumida por el $77 \%$ de la población que contribuye con $84 \%$ del Producto Interno Bruto (PIB) y en contraste, el $72 \%$ del agua disponible es consumida por el 23\% de la población que contribuye con el 16\% del PIB.

\section{Situación hidrológica local}

La Comisión Nacional de Población (CONAPO), en su informe correspondiente al 2005 señala que la población de 18'620,763 habitantes concentrados en un área de 4,979 kilómetros cuadrados y una densidad poblacional de 3,740 personas por kilometro cuadrado hacen que se considere al servicio intermitente de agua potable como la principal problemática. En la ZMVM, durante el periodo que va de 1950 al año 2000, la población ha aumentado 5.25 veces pasó de 3’442,557 habitantes a 18’076,572 residentes. En la ZMVM habitan cerca de 21 millones de personas de las cuales 7 millones tienen menos de 15 años siendo la mitad mujeres y 12 de millones los que habitan en el Estado de México. Respecto a la densidad poblacional el Estado de México y el Distrito Federal son la primer y segunda entidades con más viviendas ocupadas siendo la delegación Iztapalapa la más poblada con 1750336 de los cuales la mitad son menores de 15 años.

La CONAGUA (2010) al evaluar los porcentajes de calidad del agua superficial de 393 estaciones en 225 ríos, 81 estaciones en 62 lagos y presas, 26 estaciones en 13 santuarios y sitios costeros, 15 estaciones de des- 
carga de aguas residuales, así como de la subterránea que consta de 228 estaciones en 24 acuíferos, estableció el Î́ndice de Calidad del Agua con valores entre 0 y 100, siendo este último valor excelente, después aceptable, levemente contaminada, contaminada, fuertemente contaminada, y el último como excesivamente contaminada. Demostró que el $60.7 \%$ del agua superficial y el $46.3 \%$ de subterránea están contaminadas y fuertemente contaminadas, clasificando al agua superficial del Valle de México como excesivamente contaminada con un 32.49 (véase gráfico 3).

\section{Gráfico 3. Situación hidrológica local}

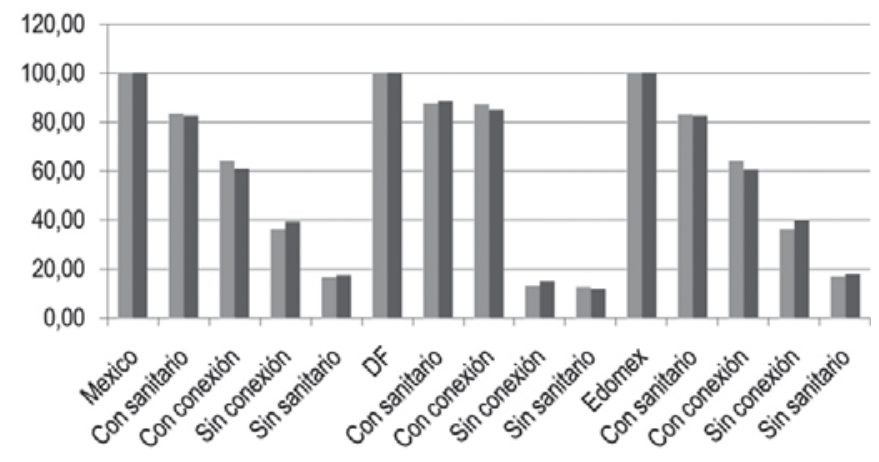

Fuente: OCDE (2010)

m viviendas = Ocupantes

Debido a que la ZMVM es de alto riesgo hidrológico sólo se han restringido las concesiones para la explotación a menos de $3000 \mathrm{~km}^{3}$, el $78 \%$ es extraído de las tomas superficiales y el $22 \%$ de las tomas subterráneas. El 48\% destinado a la agricultura, el $46 \%$ a la industria y el 6 al servicio público. La CONAGUA (2010) señala que la disponibilidad del agua por región hidrológica (m3/habitantes/año), en la Zona Metropolitana del Valle de México, esta clasificada como baja siendo la causa principal del abasto irregular de agua. Las inversiones del subsector en zonas urbanas fueron en la ZMVM de 394.200 pesos y se canalizaron única y exclusivamente al saneamiento de aguas residuales. El suministro de agua en la ZMVM es de $68 \mathrm{~m}^{3} / \mathrm{seg}$. los cuales provienen de pozos explotados 25.16 $\mathrm{m}^{3} / \mathrm{seg}$. (37\%), pozos recargados $15 \mathrm{~m}^{3} / \mathrm{seg}$. (22\%), manantiales $.36 \mathrm{~m}^{3} /$ seg. (2\%), del Río Cutzamala $13.6 \mathrm{~m}^{3} / \mathrm{seg}$. (20\%) del Río Lerma $6.12 \mathrm{~m}^{3}$ / seg. (9\%) y saneamiento con $6.8 \mathrm{~m}^{3} / \mathrm{seg}$. (10\%). Respecto al grado de presión del recurso, la ZMVM ocupa el primer lugar con una sobreexplotación del 120\% del agua disponible. A pesar de que la situación hidrológica es extremadamente comprometida en la ZMVM, las demás regiones hidrológicas se encuentran muy cercanas a dicha problemática. Las zonas norte, noreste y centro explotan el $40 \%$ de sus recursos hidrológicos. 
En 1955 los habitantes de la Ciudad de México tenían una disponibilidad de 11500 metros cúbicos anuales per cápita. En el año 2004 disminuyó a 4094 metros cúbicos anuales per cápita. En ese mismo año se consumió el 74 por ciento del total de agua potable suministrada equivalente a 16.157 metros cúbicos por segundo (CONAGUA, 2010). El agua en el Distrito Federal, esta destinada a la industria (17\%), el comercio (16\%) y uso domestico (67\%) el cual se divide en el uso de excusado (40\%), regadera (30\%), ropa (15\%), trastes (6\%), cocina $(5 \%)$ y otros $(4 \%)$.

Iztapalapa al concentrar la mayor población obtuvo el mayor consumo con 2.732 metros cúbicos por segundo equivalentes al 16.9 por ciento del total. Gustavo A. Madero y Álvaro Obregón con 13.75 y 9.94 por ciento respectivamente. En contraste, las delegaciones con menor consumo fueron Cuajimalpa, Tláhuac y Milpa Alta con un 5.97 por ciento. En este sentido, se espera para el 2020 una disponibilidad de 3500 metros cúbicos anuales per cápita. Por ello la cobertura del servicio es excluyente con 905 000 personas que no cuentan con agua potable porque hay una escasez de seis metros cúbicos por segundo.

En el caso del consumo doméstico de agua los criterios para establecer la escasez son:

- Crítica entre 1000 y 1700 metros cúbicos anuales per cápita

- Baja entre 1700 y 5000 metros cúbicos anuales per cápita

- Media entre 5000 y 10000 metros cúbicos anuales per cápita

- Alta más de 10000 metros cúbicos anuales per cápita

El 32.27 por ciento de los usuarios se encuentra dentro del umbral del rango, el 78.5 por ciento tiene un consumo menor a 50 metros cúbicos, el 11 por ciento consume menos de 10 metros cúbicos y 0.38 consume más de 180 metros cúbicos bimestrales. El pago promedio en la Ciudad de México de 110.25 pesos bimestrales. Esto significa una recaudación por cobro de derechos a los usuarios del 80 por ciento en relación a su costo real por el servicio.

\section{Situación hidrológica prospectiva}

Debido a factores hidrológicos, económicos, políticos y sociales, en el año 2025 la ONU (2010) pronostica una extremadamente escasa disponibilidad de agua para la ZMVM (véase gráfico 4).

La Comisión Nacional de Población (CONAPO) en su informe de 2005 ha proyectado para el año 2030 el crecimiento poblacional de 32 ciudades con más de 500000 habitantes destacando la Zona Metropolitana del Valle de México (ZMVM) con 22.5 millones de habitantes, la Zona Metropolitana de Guadalajara (ZMG) con 4.8 millones de habitantes y la Zona Metropolitana de Monterrey (ZMM) con 4.9 millones de habitantes. La problemática de distribución de los recursos hídricos se enfocaría en 
aquellas ciudades con una población mayor a los 500 mil habitantes. Si se consideran las proyecciones poblacionales, las zonas metropolitanas de Guadalajara, Monterrey, Cuernavaca, Tlaxcala, Veracruz, Puebla, Aguascalientes, Toluca, San Luis y Cancún estarían en una crisis de disponibilidad hídrica esperada para el año 2025

\section{Gráfico 4. Situación hidrológica prospectiva}
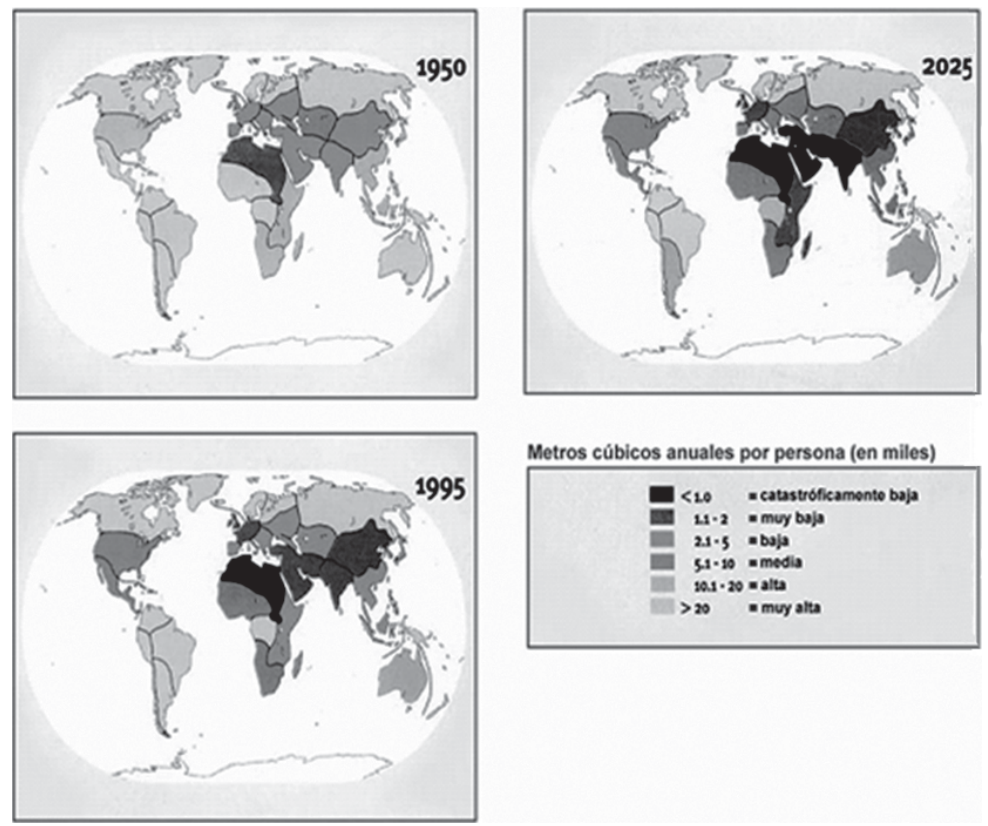

Metros cúbicos anuales por persona (en miles)

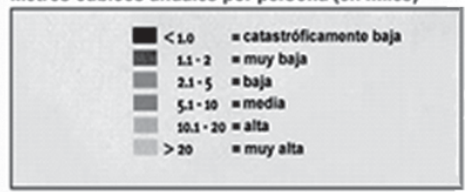

Fuente: ONU (2010)

\section{Estudios psicológicos de la sustentabilidad}

Las Psicologías de la Sustentabilidad son once subdisciplinas avocadas al estudio de los estilos sustentable derivados de situaciones ambientales. Los conceptos esenciales de las once subdisciplinas (ver tabla 1) se articulan en una estructura de factores temporales, espaciales, situacionales, económicos, culturales y psicológicos predictores del comportamiento que extrae, procesa, distribuye, consume, reutiliza y recicla los recursos naturales en función de sus necesidades actuales y las necesidades de sus generaciones posteriores. 
Tabla 1. La Psicología de la Sustentabilidad

\begin{tabular}{|c|c|c|c|c|}
\hline Año & Autor & Psicología & Explicación(Erklärung) & Comprensión(Verstehen) \\
\hline 1879 & Wunt & Ėtnica & & $\sqrt{ }$ \\
\hline 1910 & McDougal & Social & & $\sqrt{ }$ \\
\hline 1911 & Hellpach & Ambiental & & $\sqrt{ }$ \\
\hline 1935 & Muchow & Arquitectónica & & $\sqrt{ }$ \\
\hline 1953 & Skinner & Conductista & $\sqrt{ }$ & \\
\hline 1968 & Barker & Ecológica & $\sqrt{ }$ & \\
\hline 1974 & Everett & Conservacionista & $\sqrt{ }$ & \\
\hline 1974 & Sarason & Comunitaria & & $\sqrt{ }$ \\
\hline 1980 & Berk, et. al, & Hídrica & $\sqrt{ }$ & \\
\hline 1989 & Crawford \& Anderson & Evolucionista & $\sqrt{ }$ & \\
\hline 1990 & Seligman & Positiva & v & \\
\hline
\end{tabular}

En 1854 Seattle (Ce-atl / líder-agua), jefe máximo de los Pieles Rojas, respondía a la oferta de reubicación propuesta por Washington:

“¿Cómo se puede comprar o vender el firmamento, ni aún el calor de la tierra? Si no somos dueños de la frescura del aire ni del fulgor de las aguas, ¿cómo podrían ustedes comprarlas? Cada parcela de esta tierra es sagrada para mi pueblo. Cada brillante mata de pino, cada grano de arena en las playas, cada gota de rocío en los oscuros bosques, cada altozano, es sagrado a la memoria y al pasado de mi pueblo. La savia que circula por las venas de los árboles lleva consigo las memorias de los pieles rojas. Somos parte de la tierra y ella es parte de nosotros. Las flores perfumadas son nuestras hermanas; el venado, el caballo, el águila; éstos son nuestros hermanos. Las escarpadas peñas, los húmedos prados todos pertenecemos a la misma familia.”

Y sobre el agua decía:

"El agua cristalina que corre por ríos y arroyuelos no es solamente agua, sino también representa la sangre de nuestros antepasados. El murmullo del agua es la voz del padre de mi padre (...) y cada reflejo en las claras aguas de los lagos cuenta los sucesos y memorias de las vidas de nuestras gentes."

Las Ciencias Sociales, tienen en sus cimientos, palabras tales como; tribu, campo, espíritu, alma, sentimiento y recuerdo a partir de las cuales Dilthey las llamó "Ciencias del Espíritu” (Geisteswissenschaften) para diferenciarlas de las “Ciencias de la Naturaleza” (Naturwissenschaften). Posteriormente, Weber definió a las CS como comprensivas (Verstehen) y a las CN como explicativas (Erklärung). Por ello, el inicio de la psicología es étnico, buscaba comprender.

En 1879 Wunt publicó un libro que llamo "Psicología de los Pueblos" a partir de la cual se derivan las variables de "espíritu” en torno a la relación entre las especies y la naturaleza. Wunt consideraba que los sím- 
bolos y significados no estaban separados y el pueblo percibía los recursos naturales de tal manera que eran un elemento del pueblo y se fusionaban con el pueblo mismo. La gente respetaba el entorno porque eran un elemento del pueblo inseparable a su introspección y convivencia. El agua (wasser), la psicología (psychologie) y el pueblo (volks) formaban un solo espíritu (geist).

En 1910 McDougal, con el nombre de "Psicología Social”, registra una publicación y acuña el término de "mente social” para relacionarlo con el de "espíritu de los pueblos" propuesto por Wunt para comprender los procesos de identidad en torno a la naturaleza. Es decir, el respeto por los recursos parecía derivarse de ese espíritu o mente propuestos por éstas dos aproximaciones. La mente y el espíritu se separan, la naturaleza y la psicología empiezan a separarse.

En 1911 Hellpach propuso el concepto de “ambiente fáctico” y su impacto en la psique a lo cual llama "psique de lo fáctico”. Aquí aparece el entorno relacionado con la psique humana. Una vez separadas la psique, la mente y el espíritu, la naturaleza es percibida y con ello incluida en el mundo de lo real. La naturaleza y la psique, una vez separadas, pueden analizarse separando sus partes en relaciones para después estudiar su variación y con ello su medición y predicción.

En 1935 Muchow exportó la psicología arquitectónica a los Estados Unidos para explicar el impacto del diseño y edificaciones sobre el comportamiento humano. La sociedad demandaba espacios, diseños y edificaciones que los aseguraran de la incertidumbre que vivieron durante la primera y segunda guerra mundial. Se trataba de una psicología arquitectónica que a partir de los valores de seguridad, orden y progreso promovía los valores de la modernidad urbana avocada al control de los recursos naturales. Entre la naturaleza y la humanidad se encuentra la arquitectura sustentada en una psicología de la certidumbre y la seguridad.

En 1953 Skinner realizó análisis experimentales de las "relaciones contingentes" entre el comportamiento condicionado y los "estímulos discriminativos" que anteceden a los reforzadores. Este autor descubre que el entorno y el comportamiento humano parecían estar mediados por procesos psicológicos.

En 1968 Barker hizo inteligible la dimensión del "espacio ecológico" como el determinante del comportamiento humano. El cuidado de los recursos estaba determinado por el espacio individual. A mayor espacio personal le correspondía una alta probabilidad de conservación de los recursos. La psicología modera; la relación entre la naturaleza y la humanidad, entre la disponibilidad de los recursos y las necesidades.

En 1974 Everett refiere al constructo esencial de "conducta ecológica responsable” en relación al desarrollo de las economías norteamericanas, asiáticas y europeas del Pacífico y Atlántico cuyas necesidades energéticas 
las llevan a incrementar la explotación de los recursos naturales. La psicología de la conservación sintetiza los conceptos abstractos de sus antecesoras para explicar el consumismo y los efectos en la salud de la contaminación atmosférica. La conservación de los recursos era la resultante de la relación entorno-comportamiento. La psicología parece haber abandonada la "comprensión" para avocarse a la "explicación" de la naturaleza con base en las necesidades humanas. No obstante, en el mismo año, Sarason propone el concepto de "Sentimiento de Comunidad" para comprender el efecto de las enfermedades en los asentamientos humanos. Se trata de una aproximación sanitaria en la que la insalubridad, derivada de la escasez y abasto irregular de agua, tiene un efecto directo sobre la dinámica comunitaria.

En 1980 Berk, Cooley, LaCivita, Parker, Sredl y Brewer publican un artículo sobre la reducción del consumo de agua en una situación de escasez. Los estudios psicológicos de la sustentabilidad, para explicar el impacto de la escasez, desabasto e insalubridad del agua sobre el comportamiento humano recuperan el conocimiento de las subdisciplinas expuestas para demostrar la premisa de conservación a partir de los costos y beneficios en el consumo de agua.

En 1989 Crawford y Anderson desde una aproximación evolucionista, relacionaron el comportamiento anti-ambiental con los mecanismos psicológicos básicos a partir de las cuales las especies compiten por la obtención de recursos y con ello participan en la selección de especies adaptándose al entorno. En esta carrera por la supervivencia, las especies animales y vegetales, adoptan estilos de vida que los llevan, instintiva y psíquicamente, a la competencia y el almacenamiento de los recursos. Ambos estilos evolutivos garantizaron la adaptación de la especie a su entorno. Sin embargo, el medio ambiente en el que las especies compiten, cambia constantemente y toda adaptación por vía de la competencia es posterior a las exigencias del entorno.

Finalmente, en 1990 Seligman escribe un influyente libro: "El Optimismo Aprendido" en el que sostiene que las personas dedicadas, optimistas y atemporales construyen un mundo de felicidad a partir del cual aprenden a reconocer sus necesidades en función de sus motivos, esfuerzos y logros. Incluso, las personas felices, transmiten este aprendizaje a sus grupos de pertenencia y referencia mediante los procesos de identidad e influencia social. La psicología de la sustentabilidad adopta los postulados de la psicología positiva para explicar los comportamientos pro-sustentables.

En un contexto de racionalidad de costos y beneficios, las psicologías de la sustentabilidad adoptaron los métodos de la psicología de la conservación y soslayaron los métodos de la psicología de la comunidad. La vertiente conservacionista prosperó y hasta el momento es el paradigma dominante. La vertiente comunitaria parece retornar con los estudios de representación social y sentimiento comunitario. Sin embargo, la vertiente conservacionista se ha radicalizado al plantear una omnisciencia conside- 
rando que el comportamiento es un reflejo codificado genéticamente y que predispone a las personas a afrontar las situaciones ambientales.

Una vez expuesta la historia de la psicología de la sustentabilidad, se exponen las psicológicas de la sustentabilidad hídrica.

El nacimiento de las Psicologías de la Sustentabilidad Hídrica tiene como fecha de registro el año de 1980 cuando Berk, Cooley, LaCivita, Parker, Sredl y Brewer llevan cabo un estudio sobre la relación causal, directa y significativa entre la escasez y el ahorro de agua. Transcurridos 31 años de investigación en torno al agua (ver tabla 2), pueden observarse dos líneas de investigación que parten de los planteamientos “comprensivos” y "explicativos". Se trata de una vertiente orientada a la explicación de la sustentabilidad y otra vertiente orientada a la comprensión de la sustentabilidad.

\section{Tabla 2. Las Psicologías de la Sustentabilidad Hídrica}

\begin{tabular}{|c|c|c|c|c|c|}
\hline Año & Autor & Vertiente & Concepto & $\begin{array}{l}\text { Explicación } \\
\text { (Erklänung) }\end{array}$ & $\begin{array}{c}\text { Comprensión } \\
\text { (Verstehen) }\end{array}$ \\
\hline 1980 & Berk, et. al, & Conservacionista & Escasez y Ahorro & $\sqrt{ }$ & \\
\hline 1991 & $\begin{array}{l}\text { Thompson } \\
\text { Stoutemeyer, }\end{array}$ & Conservacionista & Dilemma de los Comunes & $\sqrt{ }$ & \\
\hline 1994 & Aitken, et. al, & Conservacionista & Ahorro Residencial & $\sqrt{ }$ & \\
\hline 2002 & Rodríguez, et. al, & Comunitarista & Representación Social & & $\sqrt{ }$ \\
\hline 2002 & Bustos, et. al, & Conservacionista & $\begin{array}{l}\text { Motivos y Percepción de } \\
\text { Riesgo }\end{array}$ & $\sqrt{ }$ & \\
\hline 2002 & Martínportugués, et. al, & Conservacionista & Actitudes hacia el Consumo & $\sqrt{ }$ & \\
\hline 2002 & Espinosa, et. al, & Conservacionista & Estructura de Competencias & $\sqrt{ }$ & \\
\hline 2003 & Bemard & Comunitarista & Creencias Espirituales & & $\sqrt{ }$ \\
\hline 2003 & Corral & Conservacionista & Estructura Situacional & $\sqrt{ }$ & \\
\hline 2004 & Navarro & Comunitarista & Representación Social & & $\sqrt{ }$ \\
\hline 2004 & Bridgeman & Conservacionista & Percepción de Reciclaje & $\sqrt{ }$ & \\
\hline 2004 & Syme, et. al, & Conservacionista & Predicción del Consumo & $\sqrt{ }$ & \\
\hline 2004 & Bustos, et. al, & Conservacionista & $\begin{array}{l}\text { Predicción de } \\
\text { Conservación }\end{array}$ & $\sqrt{ }$ & \\
\hline 2004 & Martínez & Conservacionista & $\begin{array}{l}\text { Estructura } \\
\text { Responsabilidades }\end{array}$ & $\sqrt{ }$ & \\
\hline 2004 & Bustos & Conservacionista & Modelo de Conservación & $\sqrt{ }$ & \\
\hline 2004 & Bustos, et. al, & Conservacionista & Atribución & $\sqrt{ }$ & \\
\hline 2004 & Valenzuela, et. al, & Conservacionista & $\begin{array}{l}\text { Austeridad, Altruismo y } \\
\text { Propensión }\end{array}$ & $\sqrt{ }$ & \\
\hline 2006 & Corral \& Frías & Conservacionista & Creencias Normativas & $\sqrt{ }$ & \\
\hline 2006 & Corral, et. al, & Conservacionista & Conducta Sustentable & $\sqrt{ }$ & \\
\hline 2006 & Tall, et. al, & Conservacionista & Evolucionismo & $\sqrt{ }$ & \\
\hline 2008 & Zhao \& Chen & Comunitarista & Tasación Borrosa & & $\sqrt{ }$ \\
\hline 2008 & Bonaiuto, et. al, & Comunitarista & Identidad Diferencial & & $\mathrm{V}$ \\
\hline 2008 & Xin & Conservacionista & Sustentabilidad Doméstica & V & \\
\hline 2008 & Corral, et. al, & Conservacionista & Registro del Consumo & V & \\
\hline 2008 & Corral, et. al, & Conservacionista & $\begin{array}{l}\text { Creencias y Principios } \\
\text { Sustentables }\end{array}$ & V & \\
\hline 2008 & Weekes & Comunitarista & Participación Ciudadana & & V \\
\hline 2009 & March y Sauri & Conservacionista & Determinantes Geoespaciales & V & \\
\hline 2010 & Chang, et. al, & Conservacionista & Variaciones Espaciales & V & \\
\hline 2010 & Rusell \& Fielding & Comunitarista & $\begin{array}{l}\text { Administración de } \\
\text { Demanda }\end{array}$ & & V \\
\hline 2010 & Kallis, et. al, & Comunitarista & Conservación Pública & & V \\
\hline 2010 & Marandu, et. al, & Conservacionista & Predicción Residencial & V & \\
\hline 2010 & Erlene & Conservacionista & Manejo de Conservación & V & \\
\hline 2011 & Mondéjar, et. al, & Conservacionista & Estructura de Ahorro & V & \\
\hline
\end{tabular}


Las psicologías conservacionistas, a través de modelos estructurales, buscan la predicción de los comportamientos anti y pro-sustentables. Han demostrado las relaciones indirectas y directas, negativas y positivas, insignificantes y significantes entre los indicadores y los constructos de primer y segundo orden. Hasta el momento, no existe un consenso en la conceptuación, pero si en la operacionalización, medición, análisis y síntesis de dichas variables y sus relaciones entre ellas (véase figura 1).

\section{Figura 1. Estudios de la sustentabilidad}

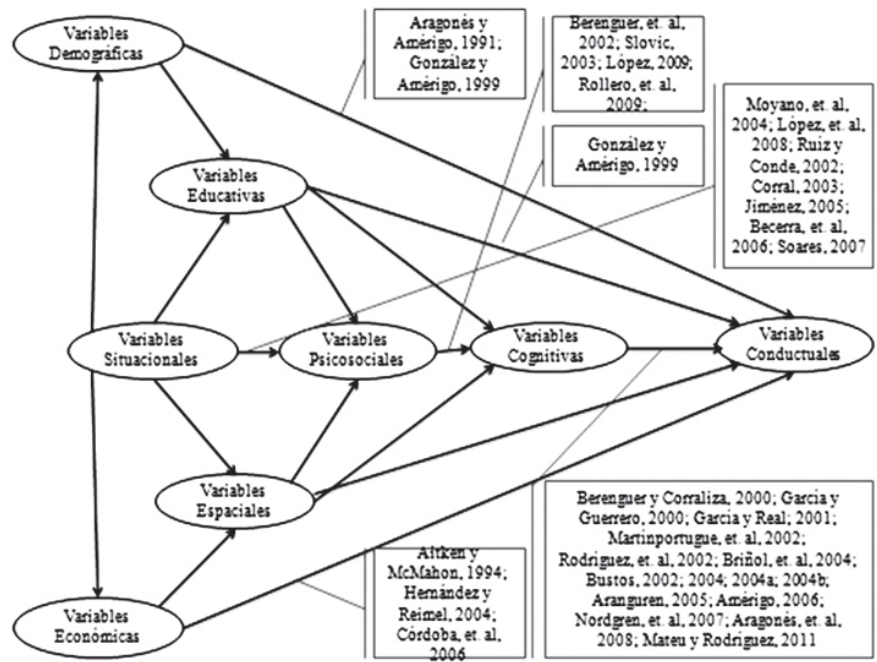

\section{Estudios actitudinales}

El análisis de las actitudes hacia el Desarrollo Sustentable puede llevarse a cabo considerando los planteamientos de la Teoría de la Disonancia Cognitiva (TDC) de León Festinger, la Teoría de la Acción Razonada (TAR) de Icek Ajzen y Martín Fishbein, la Teoría del Comportamiento Planificado (TCP) de Icek Ajzen, la Teoría de la Probabilidad de Elaboración (TPE) de Richard Petty y John Cacioppo y la Teoría del Procesamiento Espontáneo (TPE) de Russell Fazio. Cada teoría abona conceptos y relaciones causales entre variables sociodemográficas, cognitivas y comportamentales para la construcción de una teoría actitudinal relativa al Desarrollo Sustentable.

Las actitudes han sido definidas como evaluaciones negativas o positivas, desfavorables o favorables, implícitas o explícitas, emotivas o 
deliberadas, improvisadas o planificadas, heurísticas o sistemáticas hacia objetos, personas o procesos al momento de ser aprendidas por la influencia de un grupo o sistema persuasivo y organizadas para responder eficiente, eficaz y efectivamente ante una situación imponderable, impredecible e incontrolable.

Los estudios psicológicos han desarrollado dos modelos para predecir el comportamieno deliberado, planificado y sistemático. Se trata del Modelo de la Acción Razonada (MRA por sus siglas en ingles) y el Modelo del Comportamiento Planificado (MPB).

\section{Figura 2. Modelo de Acción Razonada}

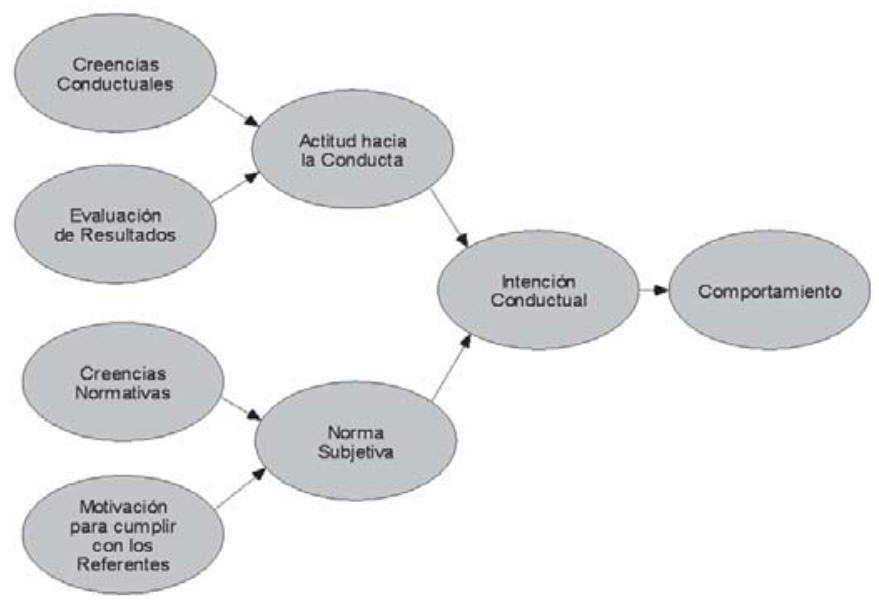

Fuente: Ajzen y Fishbein (1974)

Ajzen y Fishbein (1974) propusieron el MRA para explicar los hechos observablemente deliberados que llevan a cabo personas a partir de sus expectativas, creencias y evaluaciones en torno a un objeto, persona o proceso. Se trata del primer acercamiento a la predicción del comportamiento considerando las relaciones causales de variables circunscritas a un sistema cognitivo como determinantes del accionar humano. El MRA es un sistema cognitivo en el que las normas y creencias son consideradas variables exógenas que relacionan al MRA con otras variables de orden cultural. En dicho sistema cognitivo, las actitudes y las normas personales transmiten los efectos externos de las variables evaluativas, normativas y creenciales. Otra variable fundamental es la intención conductual que no sólo transmite los efectos de las otras variables. Además delimita la predicción del accio- 
nar humano en un contexto de decisiones que incrementan la probabilidad de llevar a cabo una acción favorable o desfavorable al procesamiento deliberado de la información (véase figura 2).

Sin embargo, Ajzen y Fishbein serían los primeros autores en reconocer los límites del MRA al considerar que la generalidad de una variable antecedente no podría explicar o predecir la especificidad de una variable consecuente. A decir de estos autores, las relaciones causales entre las variables debían de tener el mismo nivel de especificidad para entablar una asociación significativa.

Ajzen (1991) elaboró el Modelo del Comportamiento Planificado (MPB) acorde a los límites del MRA para explicar o predecir el comportamiento deliberado y planificado. En principio, la incidencia de variables normativas y evaluativas externas al sistema cognitivo fue delimitada. Es decir, el comportamiento planificado es un comportamiento deliberadamente sistemático en el que las creencias son sus determinantes indirectos y las intenciones junto con la situación de control son sus determinantes directas. En la medida en que un individuo adopta creencias relativas a un objeto, proceso o persona incrementa sus probabilidades de llevar a cabo un acto deliberado y planificado. El MPB es un sistema cognitivo delimitado de creencias relacionadas casualmente con actitudes, percepciones, normas e intenciones sistemáticas alrededor de comportamiento (véase figura 3).

\section{Figura 3. Modelo del Comportamiento Planificado}

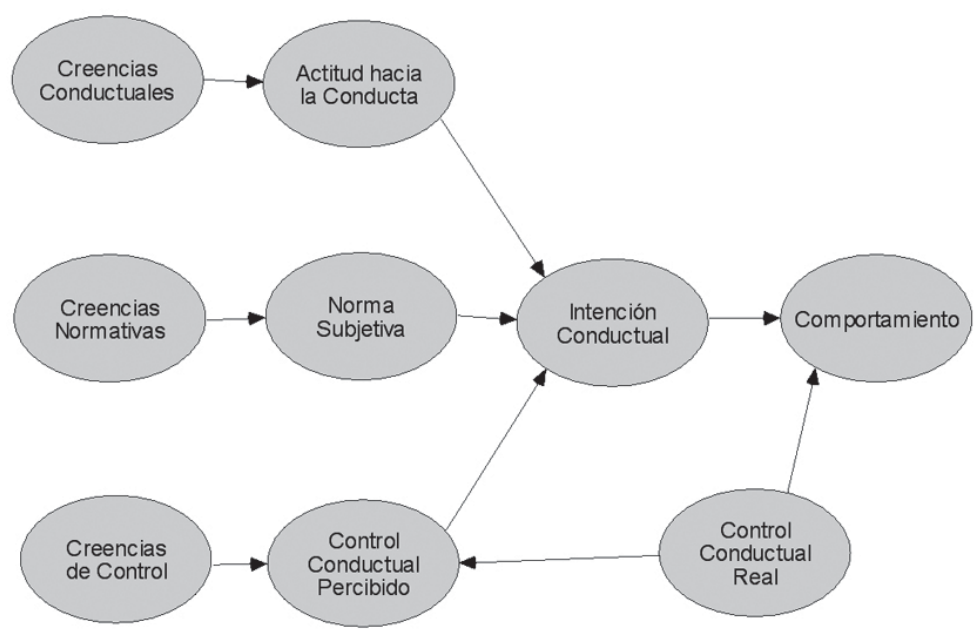

Fuente: Ajzen (1991) 
No obstante que las teorías actitudinales se avocan a explicar y predecir un comportamiento específico, deliberado, planificado y sistemático, tienden a relacionar o mediar la relación entre factores exógenos a la cognición humana y los factores comportamentales.

Otro aspecto relevante de las teorías actitudinales estriba en el proceso lógico deductivo por el que un individuo atraviesa hasta lograr un propósito y sobre todo una meta inesperada puesto que su racionalidad está acompañada de afectividad que hace más espontáneo al comportamiento.

Sin embargo, respecto al Desarrollo Sustentable, las actitudes sólo han sido relacionadas con valores, evaluaciones, percepciones, creencias, motivos e intenciones a partir del supuesto de razonamiento, planificación y sistematización del comportamiento humano más que de su determinación por la disponibilidad de recursos.

A diferencia de otros objeto actitudinales, el Desarrollo Sustentable confiere especial importancia a la propensión al futuro la cual ha sido relacionada con decisiones y comportamientos deliberados, planificados y sistemáticos.

No obstante, la propensión al futuro al estar indicada por el grado de expectativas de disponibilidad de los recursos constriñe toda posibilidad de elección orientada al uso de los recursos que hasta el momento fue decidida por las generaciones antropocéntricas. Es decir, el impacto de una escasez está mediado por la actitud. Si se considera que los individuos asumen posturas de dispendio cuando asocian la abundancia de recursos con el dispendio, entonces es de esperar que el comportamiento en el futuro sea similar al comportamiento del pasado.

Cada una de las teorías actitudinales asume que los individuos están próximos a llevar a cabo sus decisiones siempre y cuando los factores cognitivos estén consecutivamente procesados para lograr el objetivo. Esto denota la imposibilidad de disuadir a un comportamiento deliberado, planificado y sistemático. En tanto que se trata de un procesamiento lógicodeductivo, lleva al decisor a asumir los beneficios frente a los costos de oportunidad. En tal sentido, la actitud hacia al Desarrollo Sustentable parece sólo reflejar los imperativos de austeridad, propensión al futuro o aversión a los riesgos que caracterizan a los individuos y grupos ecocéntricos. La actitud hacia la sustentabilidad estaría alejada de los normas, valores, creencias, conocimientos, motivos, percepciones, competencias, habilidades y comportamientos antropocéntricos que en términos de elección colectiva representarían el mayor porcentaje de los adherentes.

Es así como la actitud hacia la sustentabilidad implica la inclusión de grupos e individuos ecocéntricos y antropocéntricos. Cada uno de ellos implica el dilema relativo al crecimiento económico a costa del deterioro ambiental. Es decir, cada postura refleja las crisis económicas estructurales a partir de la escasez de recursos. Una actitud proactiva, competente con la 
anticipación de crisis que reactivan el ciclo austero de consumo o incentivan el crecimiento sustentado en saberes y racionalidades sobre la distribución de recursos frente a la diversificación del consumo. La actitud hacia el medio ambiente regulará la incidencia de factores externos a la cognición humana

Los estudios psicológicos actitudinales se han enfocado en su conceptualización, formación, activación, accesibilidad, estructura, función, predicción, cambio, inoculación, identidad y ambivalencia (Ajzen, 2001). Las actitudes han sido definidas a partir de dimensiones afectivas y racionales. Ambas dimensiones son el resultado de experiencias y expectativas (Ajzen 2002). Esto implica su estructura: unidimensional o multidimensional que se configura en factores exógenos y endógenos (Schwartz y Bohner, 2001). Es decir, cuando las actitudes activan decisiones y comportamientos causan un proceso periférico, emotivo, espontáneo, heurístico y ambivalente (Guering, 1994). En contraste, cuando las actitudes transmiten los efectos de valores y creencias sobre las intenciones y acciones, son mediadoras endógenas de un proceso central, racional, deliberado, planificado y sistemático.

Los estudios psicológicos han demostrado diferencias significativas entre las actitudes hacia personas y actitudes hacia objetos (Ajzen y Fishbein, 1974). Las primeras se refieren a estereotipos o atributos y las segundas se refieren a evaluaciones o disposiciones. En ambas, la ambivalencia es un indicador de cambio cuando interaccionan creencias y evaluaciones formando disposiciones negativas y positivas hacia el objeto. Los conflictos se forman al interior de los componentes formados por creencias hacia el objeto. La resistencia a la persuasión, es una consecuencia de la ambivalencia actitudinal. Si el entorno amenaza la formación y la función de las actitudes éstas adaptaran al individuo ante las contingencias. De este modo, las actitudes poseen dos funciones esenciales: egoístas y utilitaristas.

En el marco de las teorías actitudinales, el cambio actitudinal alude a emociones y afectos consecuentes a los actos individuales y de los cuales las personas se sienten responsables (Arbuthnott, 2008). También se trata de la influencia social que ejercen los grupos de pertenencia o referencia sobre los individuos (Brewer y Kramer, 1985). O bien, la recepción de mensajes persuasivos orientados al razonamiento central, o mensajes persuasivos dirigidos a la emotividad periférica (Petty y Cacioppo, 1986b). En general, el sistema actitudinal es sensible a la inestabilidad del objeto y a las variaciones cognitivas que inciden en la consistencia, estabilidad, predicción, competencia o moralidad del individuo.

El cambio consistente de actitudes está relacionado con su estructura multidimensional resultante de la presión mayoritaria. La diversidad de dimensiones implica una construcción consistente del cambio actitudinal (Smith y Hogg, 2008). Es decir, las actitudes asumen una función de respuestas internalizadas ante situaciones constantes enmarcadas por los medios de comunicación masiva. 
El cambio actitudinal está relacionado con el principio disuasivo de la inoculación. Antes del ataque de mensajes persuasivos, se induce la percepción de amenazas, riesgo e incertidumbre (Cacioppo y Petty, 1989). En general, la sobreexposición a mensajes persuasivos induce una alta elaboración y con ello la persuasión (Petty y Cacioppo, 1986a). La emisión masiva de mensajes persuasivos, la motivación y las habilidades de manejo consecuentes pueden derivar en indefensión. Es decir, ante la ola de información las personas reducen su percepción de control y tienden a creer que los eventos son inconmensurables, impredecibles e incontrolables (Cacioppo, Petty, Feng y Rodríguez 1986). O bien, los individuos se forman una identidad que consiste en identificarse con un endogrupo en referencia a un exogrupo (Wood, 2000). En el proceso de indefensión, el individuo construye el cambio de actitud y su reforzamiento de desesperanza. En el proceso identitario, es el grupo el que influye en el cambio actitudinal de la persona. La indefensión es un proceso de autovalidación o profecía autocumplica. En contraste, la identidad es una validación convergente de normas grupales.

La influencia social del grupo de pertenencia o referencia alude a las normas mayoritarias y a los principios minoritarios orientados al cambio actitudinal (Crano y Prislin, 2006). La influencia de las mayorías propicia la conformidad individual y los principios minoritarios, el conflicto y el cambio actitudinal. Recientemente, el estilo de la minoría ha resultado ser el factor de influencia social y cambio actitudinal más permanente (Dovidio, Gaertner y Saguy, 2009). Es decir, la construcción de consensos mayoritarios parece tener un efecto efímero y la construcción de disensos parece ofrecer un cambio constante.

Los estudios psicológicos de la sustentabilidad hídrica han demostrado la configuración de actitudes hacia el emplazamiento, provisión, almacenamiento, acaparamiento, dosificación, reutilización, reparación de fugas, adopción de tecnologías y subsidios, incentivos, sanciones y pagos de tarifas (Leiserowitz, Kates y Parris, 2006). La hidratación, rehidratación y deshidratación son temas infrecuentes en las investigaciones de la sustentabilidad hídrica. Sólo en los estudios de Bustos (2004); Bustos, Flores y Andrade (2002); Bustos, Flores y Andrade (2004); Bustos Flores, Barrientos y Martínez (2004) el consumo de agua para la preparación de alimentos ha sido explicado a partir de las percepciones, los motivos, las creencias, los conocimientos y las habilidades. En estas investigaciones, la rehidratación puede considerarse como un indicador del consumo individual y familiar de agua en la alimentación. Los motivos de protección socioambiental son factores generales que inciden en acciones específicas. El locus de control interno, las habilidades de discriminación y las habilidades efectivas son factores intermedios -ni muy generales, ni muy específicos- que influyen en la cantidad de moléculas de agua para la preparación de alimentos. En todos los casos de las variables determinantes, sus indicadores miden rasgos semi-generales e indirectos en torno a la cantidad de moléculas de agua ingerida. Precisamente, es en esta problemática metodológica en la que las actitudes subsanarían la especificidad requerida 
para la predicción de la rehidratación individual, grupal y social.

Las teorías actitudinales sostienen que en los individuos, grupos y sociedades se forman deliberadamente y se activan espontáneamente, las disposiciones que determinarán sus intenciones y comportamientos. Incluso, son estas disposiciones las que indican cambios de consumo. No obstante, las actitudes hacia la naturaleza han tenido un efecto espurio sobre el cuidado del entorno y las actitudes hacia el agua han incidido mínimamente en la cantidad de moléculas de agua consumida. Se trata de actitudes cuasigenerales relacionadas con conductas específicas. En este sentido, las actitudes hacia la rehidratación abrirían la posibilidad de explicar y predecir comportamientos favorables a la salud individual, grupal, social, cultural, generacional y ambiental en el que el agua sería un objeto actitudinal esencial de la sustentabilidad.

\section{Teoría de la Disonancia Cognitiva (TDC) de León Festinger}

En 1957 León Festinger formuló la Teoría de la Disonancia Cognitiva (TDC) para explicar los dilemas de decisión, elección y acción alusivos a información no necesariamente convergente con nuestras opiniones (Harmon, 2007). La TDC es heredera de tres paradigmas; cambio libre, proceso inducido y justificación forzada. En el albor de sus 55 años, la TDC ha enfocado su desarrollo en el cambio y reducción de la actitud a partir del cambio libre (Risen y Chen, 2010). La TDC plantea discrepancias entre los esquemas cognitivos y la información generada por dicha discrepancia (Clair y Koo, 1991). Un mensaje que es consonante con las expectativas generará respuestas consistentes.

En el caso de la sustentabilidad hídrica (balance entre el volumen de agua disponible y el volumen de agua consumido), una noticia sobre la escasez de agua afectará la cognición antropocéntrica (los recursos naturales son para el uso exclusivo de quien puede pagar su precio, costo cotización o tarifa) y generará un dispendio (consumo mayor a los 200 litros diarios por persona). En contraste, la información relativa a la extinción de recursos acorde con las creencias ecocéntricas (los recursos naturales son patrimonio de las especies vegetales y animales en las que la humanidad está incluida) tendrá como resultado un comportamiento austero indicado por un consumo inferior al promedio general.

La información referente a la disponibilidad hídrica y los esquemas cognitivos de los usuarios del servicio de agua potable estarían relacionados con los comportamientos de austeridad o de dispendio. La TDC predice un cambio de actitud ajustado a la norma antropocéntrica o ecocéntrica si los esquemas cognitivos incluyen un consumo superior al promedio personal. El ahorro y el dispendio también son explicados por la abundancia o escasez real y norma de consumo grupal. 
Si la información científica es acorde a las actitudes del receptor entonces se generará una respuesta deliberada y convergente con la información que versa sobre la disponibilidad hídrica.

\section{Teoría de la Acción Razonada (TAR) de Martín Fishbein e Icek Ajzen}

La TAR a diferencia de la TDC plantea que los dilemas pueden ser reducidos si el comportamiento es considerado como un producto de las creencias, evaluaciones, percepciones o normas. Fishbein y Ajzen (1974) sostienen que el comportamiento deliberado es propiciado por creencias en torno a la disponibilidad de recursos. Si las personas creen que existe una escasez inminente, entonces ahorraran sistemáticamente el agua. Si por el contrario, consideran que los recursos son abundantes e inagotables, tendrán un comportamiento improvisado porque la información procesada es insuficiente para decidir la optimización. Finalmente, una situación en la que la información circundante describe un escenario de escasez relativa propiciará comportamientos espontáneos de austeridad, pero sin la autogestión que caracteriza a los grupos organizados.

A pesar de que el comportamiento deliberado está motivado por la escasez de recursos, su variación determina las creencias, actitudes e intenciones. La TAR y la TDC aseguran que los dilemas de elección sobre alusivas a la escasez o abundancia de los recursos. Tal información incide en las actitudes de los usuarios y determina el volumen y tarifa de consumo, sobornos, seudoreparaciones, boicots, confrontaciones y mítines.

Sin embargo, mientras la TAR plantea un proceso causal activado por la escasez de recursos o la abundancia de agua en la red de suministro, la TDC sostiene que ambas situaciones pueden o no causar un equilibrio entre las creencias y actitudes de los usuarios toda vez que éstas buscarán equilibrar la información que no es acorde con sus creencias y al mismo instante tomarán decisiones con la información compatible a sus expectativas. Sólo en el caso de una inminente o evidente escasez buscarán reducir su consumo para mantener sólo las necesidades mínimas de higiene que se requieren.

Ambas teorías, TAR y TDC consideran que las actitudes son esenciales para la explicación del comportamiento deliberado, ambas consideran que toda acción razonada implica un programa de acción-ejecución en el que cada persona se ajusta a los designios de la razón colectiva en torno a la optimización de los recursos. Si cada individuo recibe información relativa a la escasez, entonces tenderá a su ahorro en tanto su percepción no le muestre imágenes de abundancia.

Ahora bien, tal proceso estaría incompleto si el usuario consciente de la situación no aprendiera las habilidades y conocimientos básicos para su reutilización. 
La Teoría de la Acción Razonada sostiene que las actitudes son mediadoras del efecto de las creencias sobre las intenciones y los comportamientos (Ajzen y Fishbein, 1974). Un incremento en las creencias aumenta las disposiciones hacia decisiones y acciones específicas y deliberadas. Se trata de un proceso que va de lo general en cuanto a creencias hacia lo particular en cuanto a intenciones y acciones. No obstante, el poder predictivo de las creencias generales esta acotado por la especificidad y unidimensionalidad de las actitudes. Dado que las actitudes transmiten el efecto de las creencias, delimitan sus indicadores en disposiciones probables de llevarse a cabo.

\section{Teoría del Comportamiento Planificado (TCP) de Icek Ajzen}

La Teoría del Comportamiento Planificado (TCP) considera a las creencias específicas y delimitadas en un especio y tiempo como las determinantes indirectas del comportamiento planificado (Ajzen, 1991). Las creencias referidas a las normas, percepciones y actitudes están relacionadas directa e indirectamente con el comportamiento. Tal relación está mediada por las actitudes hacia la planificación de dicho comportamiento (Ajzen, 2001).

Ajzen (1992) sostiene que la especificidad entre las creencias, percepciones, actitudes, decisiones y comportamientos no sólo estriba en el contenido psicológico sino además en el contexto deliberado y planificado. Es decir, supone un escenario en el que coexisten los eventos azarosos con los eventos controlados por la planificación personal e insistiría en un escenario específico que incidiría sobre la evaluación racional (Ajzen, Brown y Carvajal, 2004).

Si la TDC y TAR son explicativas de los dilemas de escasez y abundancia de agua como determinantes de su ahorro o dispendio, la TCP emplea tales disyuntivas para evidenciar la especificidad de un acto molecular en un acto molar. Es decir, toda creencia general predecirá una conducta colectiva y en menor medida, un acto específico. Por ello, se requiere de información alusiva al abastecimiento.

No obstante, el alto porcentaje de fugas residenciales muestra que las creencias, en tanto información específica, no resulta suficiente para activar su depuración y posterior prevención. En los barrios periféricos de las urbes, el abasto de agua implica una distribución racionalizada que determina creencias de escasez, pero es un acto deliberado y planificado dirigido al auto-abastecimiento, optimización o reutilización. En tal sentido, las problemáticas de escasez, abasto irregular y las enfermedades hidrotransmitidas evidencian el comportamiento deliberado, planificado y sistemático. Se trata de comportamientos que implican la adopción de actitudes, decisiones y comportamientos a partir de la minimización de costos y 
la maximización de beneficios. En cuanto a la formación de actitudes disidentes se ha observado que está determinada por la percepción. En la medida en que las expectativas de riesgo incrementan la inseguridad, las actitudes aumentan en su dimensión emocional o afectiva. Ambas, percepciones $\mathrm{y}$ actitudes inciden en los comportamientos de riesgo.

La Teoría de la Conducta Planificada advierte que el efecto de las creencias sobre el comportamiento esta mediado por actitudes y percepciones de control. Ante una situación o evento contingente, la percepción de control incrementa su poder predictivo de las intenciones y los comportamientos si y sólo si interactúa con disposiciones específicas. En la medida en que la percepción de control disminuye, su relación con las actitudes hace predecible un efecto espurio en las decisiones. Necesariamente, el proceso deliberado y planificado de la toma de decisiones e implementación de estrategias requiere de una percepción de control consiste con las disposiciones hacia el objeto (Ajzen, 1991).

\section{Teoría de la Probabilidad de la Elaboración (TPE) de Richard Petty y John Cacioppo}

El procesamiento cognitivo de la información es explicada por la TPE en la que las imágenes son relacionadas con emociones y los datos con razonamientos (Briñol, Petty y Tormala, 2004). La TPE explica los procesos de actitud hacia objetos que por su naturaleza discrepante propician una elaboración que puede ser emocional o racional, pero que cada individuo asume como un símbolo que ubicaría en la periferia de su cognición y al cabo de un proceso deliberativo sistemático adoptará como un argumento central de sus decisiones y acciones (Cacioppo, Petty y Kao, 1984). La TPE analiza objetos actitudinales controversiales en los que la posición del receptor será orientada a partir de su aceptación o rechazo elaborado de información proveniente de una fuente que por su grado de especialización y confiabilidad propiciará la necesidad de cognición (Rucker y Petty, 2006). La TPE sostiene que las imágenes serán sujetas de escrutinio cuando su fuente de emisión es desconocida y poco confiable.

La TPE plantea que la información circundante sobre la disponibilidad de agua puede ser procesada como un objeto escaso o abundante. Si la escasez está asociada a emociones, entonces el usuario tendrá un ahorro intermitente de agua, no sistemático puesto las emociones sólo activan un proceso periférico en el que la representación está anclada a un núcleo de significación. Al ser un proceso periférico de imágenes, las emociones cambian constantemente. Su intermitencia es causada por símbolos y significados dispersos los cuales varían en función de las situaciones.

En contraste, cuando la información cuestiona el núcleo central de las creencias alusivas a la abundancia propicia un comportamiento ahorrativo preliminar que inmediatamente se modificará, una vez que los símbo- 
los y significados relativos a la escasez determinen el cambio de actitud y modifiquen el dispendio hídrico.

\section{Teoría del Procesamiento Improvisado (TPI) de Rusell Fazio}

La TPI sostiene que el comportamiento humano es el resultado de una activación emocional guardada en la memoria y vinculada con el futuro accionar de las personas. A partir de un estimulo informativo, los individuos adoptan símbolos que al resguardarlos activarán comportamientos futuros en situaciones poco estructuradas, pero con objetivos debidamente significativos (Fazio y Olson, 2003). Es así como la actitud improvisada tendría dimensiones indicadas por asociaciones entre consumos y evaluaciones. Puesto que la TPI propone la convergencia evaluación-acción es pertinente incluir reactivos en los que se incluyen creencias y evaluaciones hacia el objeto actitudinal. El enfoque actitudinal de su improvisación se sustenta en las creencias puesto que las determinan.

A diferencia de la TDC, TAR, TCP, TPE y la TPI sostiene que la causa principal de un accionar poco definido y más bien improvisado en la significación de la experiencia previa con el objeto actitudinal. La predicción del comportamiento, no habría que buscarlo en la recepción de información, sino en su simbolización, significado y sentido.

En el caso de la disponibilidad y redistribución de agua, el planteamiento de la TPI versaría en torno al volumen per cápita y su tarifa de consumo correspondiente en comparación al costo por unidad en otras colonias y cuyo monto quedó registrado en el recibo. En la medida en que el costo por volumen cúbico tiende a disminuir el procesamiento espontáneo se intensificará. Por el contrario, a mayor costo de unidad hídrica la deliberación y el razonamiento explicarían el ahorro de agua sistemático. Es decir, el dispendio y la optimización de agua dependen de la variación del monto a pagar registrado en el recibo de agua.

Ahora bien, a pesar de que el ahorro parece ser motivado por el aumento de la tarifa de consumo y los posteriores beneficios por subsidio, el comportamiento de ahorro y optimización de agua no pueden ser considerados como sustentables puesto que dependen de la variación del consumo el cual no es constante.

En este sentido, la actitud hacia la sustentabilidad hídrica se refiere a la asociación entre el consumo de agua y la evaluación de dicho consumo. En la medida en que el consumo de agua se incrementa en referencia a su disponibilidad puede ser evaluado negativamente si ésta evaluación es efecto de una creencia ecocéntrica. Por el contrario, el consumo austero de agua se asocia a evaluaciones positivas cuando ésta precede a una creencia ecocéntrica. 
La Teoría del Procesamiento Espontáneo plantea a las actitudes como consecuencia de la activación de experiencias con el objeto actitudinal. Las actitudes son asociaciones entre evaluaciones de objetos. Una evaluación negativa incrementa la disposición y con ello la espontaneidad del comportamiento (Ajzen, 2002).

\section{Conclusión}

El presente ensayo ha relacionado conceptualmente a las teorías que versan sobre la explicación de las actitudes para establecer sus dimensiones en torno al Desarrollo Sustentable. A partir de tal revisión, es posible afirmar que la actitud hacia la sustentabilidad hídrica implica un balance entre la cantidad de agua disponible y la cantidad de agua utilizada. La relación entre la cantidad de agua disponible y el pago del consumo de agua registrado en un recibo está mediada por creencias y actitudes. Es decir, en la medida en que la disponibilidad de agua per cápita disminuye la tarifa por el pago del servicio también tiende a reducirse debido a que la información de escasez incide en las asociaciones entre evaluaciones negativas y ahorro de agua.

La actitud hacia la sustentabilidad hídrica es un proceso deliberado e improvisado, planificado y heurístico, sistemático e intermitente en referencia a la información de escasez o abundancia sobre el consumo dispendioso o ahorrativo que es considerado desfavorable o favorable a partir de criterios antropocéntricos o ecocéntricos.

Sin embargo, las creencias y actitudes pueden influir en el consumo de agua a partir de mensajes persuasivos que activarían emociones en los usuarios del servicio de agua potable para un ahorro intermitente y activarían razonamientos para un ahorro sistemático.

El presente ensayo ha descrito las relaciones entre tres problemáticas hídricas relativas a la escasez, la calidad de la redistribución y el grado de provisión que determinan las actitudes y los estilos de vida de los habitantes de la Ciudad de México.

Si bien, las problemáticas hídricas de la urbe son diversas, éstas pueden tener su origen en la dinámica de crecimiento poblacional que las ciudades han experimentado en las últimas décadas. En la medida en que la población se ha incrementado y sobretodo aglomerado en zonas de exclusión y marginación, han surgido nuevas formas de preservación del agua para garantizar la tendencia de crecimiento poblacional y su densidad correspondiente.

Sin embargo, las problemáticas hídricas de las urbes también derivarían de las políticas públicas, la inversión, infraestructura, sistema de tarifas y sanciones que han sobredimensionado la brecha hídrica entre quienes cada vez pagan menos por el servicio a pesar de que sus 
estilos de vida propician un mayor consumo de agua y quienes cada vez pagan más por el recurso hídrico a pesar de que históricamente han subsistido con un volumen mínimo de agua para satisfacer sus necesidades básicas.

En torno a las relaciones entre las problemáticas y los estilos de vida la palabra nivel de confort o zona de confort cobra un significado y un sentido fundamental para explicar la exclusión hídrica que impedirá a la Ciudad de México desarrollarse sostenida y sustentablemente.

El confort hídrico parece sintetizar las relaciones entre las problemáticas y sus efectos en los estilos de vida de los habitantes de la ciudad. Se trata de un constructo en el que las ciencias sociales se han debatido para explicar y sobretodo, comprender la dinámica de crecimiento económico que ha sido considerada como la barrera principal de la sustentabilidad hídrica.

Si el confort hídrico significa un volumen indeterminado y variable para satisfacer las necesidades y expectativas de los individuos, entonces las ciencias sociales habrían de discutir la variación de los recursos hídricos en función de la variación de las necesidades y expectativas de consumo de quienes acaparan el agua por el sólo hecho de vivir en una zona de confort en la que la disponibilidad supera el promedio local o global. La diversificación del sistema tarifario incluiría

Tarifa por estándar. La tasa por unidad de agua es independiente de la cantidad de agua consumida.

Tarifa por volumen. El precio unitario del agua depende de la cantidad que se utiliza. Se incrementa o disminuye a partir de la discrecionalidad gubernamental.

Tarifa por situación. La tasa por unidad de agua aumenta su costo durante el día y disminuye su costo durante la noche. Durante la temporada de estío se incrementa su costo y durante la temporada de lluvias disminuye su precio unitario. Es equitativo y ahorra el costo de bombeo y purificación.

Tarifa por intervalos. El precio unitario del agua se incrementa en función del volumen consumido. A partir de los intervalos de consumo se aplican precios que se incrementan conforme el consumo sobrepasa los umbrales permitidos.

Tarifas por umbrales. El precio unitario del agua es constante en tanto no rebase el umbral de confort. Una vez rebasado el consumo asignado, se aplica un incremento, lineal, logarítmico, exponencial o logístico.

Tarifa por autofinanciamiento. El costo unitario del servicio se 
establece a partir del ingreso familiar y un umbral de confort. Una vez rebasado el límite permitido, se incrementa el costo por cada volumen cubico extra.

Tarifa por subsidio. El costo unitario del servicio de agua potable implica una cuota estándar o estratificada y un subsidio en función de un umbral de confort. 


\section{Bibliografía}

Aitken, C. \& McMahon, T. (1994), "Residential water use: predictive and reducing consumption”. Journal of Applied Social Psychology. 24, 136158.

Ajzen, I. \& Fishbein, M. (1974), "Factors influencing intentions and the intention behavior relation”. Human Relations. 27, 1-15

Ídem (1991), “The Theory of Planned Behavior”. Organizational Behavior and Human Decision Processes. 50, 179-211

Ídem (1992), "Persuasive Communication Theory in social psychology: a historical perspective”. En: M. Manfredo (coord.). Influencing human behavior. Theory an applications in recreation and tourism. (pp. 1-27). Sagamore Publishen, Champaing.

Ídem (2001), “Nature an operation of attitudes”. Annual Review Psychology. $52,27-58$.

Ídem (2002), “Attitudes”. En R. Fernández Ballesteros (Ed.), Encyclopedia of Psychological Assessment. (pp. 110-115), Sage Publications, London.

Ajzen, I., Brown, T. y Carvajal, F. (2004), "Explaining the discrepancy between intentions and actions: the case of hypothetical bias in contingent valuation”. Personality and Social Psychology Bulleting. 30, 1108-1121.

Aldama, A. (2004), "El agua en México: una crisis que no debe ser ignorada”. En M. A. Villa y Saborio, E. (coord.). La gestión del agua en México: los retos para el Desarrollo Sustentable (pp. 11-31). Porrúa-UAM, México.

Arbuthnott, K. (2008), “Education for sustainable development beyond attitude change”. International Journal of Sustainability in Higher Education. 10, 152-163.

Auxiliadora, M. y Manera, J. (2003), "El análisis factorial por componentes principales”. En J. P. Levy y J. Varela (coord.). Análisis multivariable para las Ciencias Sociales. (pp. 327-360), Pearson Prentice Hall, Madrid.

Banco de México (2004), Las remesas familiares en México. Banxico, México.

Baron, R. \& Kenny, D. (1986), “The moderator and mediator variables distinction in social psychology research. Conceptual strategic, and statistical considerations”. Journal of Personality and Social Psychology. 51, 1173-1182.

Becerra, M., Sainz, J. y Muñoz, C. (2006), Los conflictos por agua en 
México. Diagnóstico y análisis. Gestión y Política Pública. 15 (1), 111143.

Bechtel, R., Asai, M., Corral, V. y González, A. (2006), “A cross cultural study of environmental beliefs structures in USA, Japan, México and Peru.” International Journal of Psychology. 41, 145-151.

Bechtel, R., Corral, V. \& Pinheiro, J. (1999), “Environmental belief systems United Status, Brazil and México”. Journal of Cross-Cultural Psychology. 30, 122-128.

Berenguer, E., Corraliza, J. y Martín, R. (2005), “Rural-urban differences in environmental concern, attitudes, and actions”. European Journal Psychology Assessment. 21, 128-138.

Berk, R. A., Cooley, T. F., LaCivita, C. J., Parker, S., Sreld, K. \& Brewer, M. B. (1980), "Reducing consumption in periods of acute scarcity: The case of water”. Social Science Research. 9, 99-120.

Bernard, P. (2003), "Ecological implications of water spirit beliefs in Southern Africa: the need to project Knowledge, Nature and Resource rights”. USDA Forest Service Proceeding RMRS-P-27 pp. 148-153.

Bonaiuto, M., Bilotta, E., Bonnes, M., Carrus, G., Ceccarelli, M. \& Martorella, H. (2008), "Local identity moderating the role of individual differences in natural resource use: the case of water consumption”. Journal of Applied Social Psychology, 38, 947-967.

Breña, F. (2004), “Gestión integral del recurso agua”. En M. Villa y E. Saborio (coord.), La gestión del agua en México: los retos para el Desarrollo Sustentable. (pp. 39-54) México: Porrúa-UAM

Brewer, M. \& Kramer, R. (1985), “The psychology of intergroups attitudes and behaviors”. Annual Review of Psychology. 36, 219-246.

Bridgeman, J. (2004), Public perception towards water recycling in California. J.CIWED, 18, 150-154.

Briñol, P., Petty, R. y Tormala, Z. (2004), “Self validation of cognitive responses to advertisements”. Journal of Consumer Research 30, 559-574.

Bustos, J. (2004), Modelo de conducta proambiental para el estudio de la conservación de agua potable. Tesis de Doctorado, Facultad de Psicología, Universidad Nacional Autónoma de México.

Bustos, J., Flores, M. y Andrade, P. (2004), "Predicción de la conservación de agua a partir de factores socio cognitivos". Medio Ambiente y Comportamiento Humano. 5, 53-70. 
Bustos, J. y Flores, L. (2000), "Evaluación de problemas ambientales, calidad del ambiente y creencias de afectación de la salud”. La Psicología Social en México. 8, 445-451.

Bustos, J., Flores, L. y Andrade, P. (2002), “Motivos y percepción de riesgos como factores antecedentes a la conservación de agua en la Ciudad de México”. La Psicología Social en México. 9, 611-617.

Bustos, J., Flores, L., Barrientos, C. y Martínez, J. (2004), “Ayudando a contrarrestar el deterioro ecológico: atribución y motivos para conservar agua”. La Psicología Social en México. 10, 521-526.

Bustos, J., Montero, M. y Flores, L. (2002), Tres diseños de intervención antecedente para promover.

Cacioppo, J. \& Petty, R. (1989), “Effects of message repetition on argument processing, recall and persuasion”. Basic and Applied Social Psychology. 10, 3-12.

Cacioppo, J., Petty, R. y Kao, C. (1984), “The efficient assessment of need for cognition”. Journal of Personality Assessment. 48, 306-309.

Cacioppo, J., Petty, R., Feng, C. \& Rodríguez, R. (1986), “Central and peripheral routes to persuasion: individual difference perspective”. Journal of Personality and Social Psychology. 51 (5), 1032-1043.

Chang. H., Parandvash, G. \& Shandas, V. (2010), "Spatial variations of single-family residential water consumption in Portland, Oregon”. Urban Geography. 31 (7), 953-972.

Chávez, R. (2004), “El manejo sustentable del agua subterránea”. En M. Villa y E. Saborio (coord.), La gestión del agua en México: los retos para el Desarrollo Sustentable. (pp. 133-138) México: Porrúa-UAM.

Comins, C, \& Chambers, S. (2005), "Psychological and situational influenses on conmuter transport mode choice”. Environment and Behavior. 37, 640-661.

Comisión Nacional del Agua (2010), Estadísticas del Agua en México. CONAGUA, México .

Consejo Nacional de Población (2005), Situación demográfica de México. CONAPO, México.

Corral, V. \& Frías, M. (2006), “Personal normative beliefs, antisocial behavior, and residential water conservation". Environment and Behavior. 38, 406-421.

Corral, V. (1998), “Interacciones ambiente / conducta: algunas áreas de 
investigación”. En V. M. Alcaraz y A. Bouzas (coords.), Las aportaciones mexicanas a la psicología. (pp. 55-70) México: UNAM.

Ídem (2000), “La definición del Comportamiento Proambiental”. La Psicología Social en México. 8, 466-472.

Ídem (2001), “Aplicaciones del Modelamiento Estructural a la investigación psicológica”. Revista Mexicana de Psicología. 18 193-209.

Ídem (2002a), “A structural model of proenvironmental competency”. Environment \& Behavior. 34, 531-549.

Ídem (2002b), “Avances y limitaciones en la medición del comportamiento proambiental”. En J. Guevara, y S. Mercado, (coord.) Temas Selectos de Psicología Ambiental. (pp. 483-510). UNAM-GRECO-UNILIBRE, México.

Ídem (2002c), “Structural Equation Modelling”, in Bechtel, R y Churcman, A. (eds.) Handbook of Environmental Psychology. (pp. 256-270). Wiley \& Sons, Inc., New York.

Ídem (2003), “Determinantes psicológicos o situacionais do comportamento de conservaçào de àgua: um modelo estructural”. Estudos de Psicología. 8, 245-252.

Ídem (2003), "Psychological and situational determinants of water conservation behavior: a structural model”. Estudos de Psicologia. 8 (2), 245-252.

Ídem (2003a), “¿Mapas cognitivos o conductas ambientales?” en E. Díaz, y M. Anaya, (coord.). Perspectivas sobre el cognitivismo en psicología. (pp. 37-79). México: UNAM (Iztacala).

Ídem (2003b), “Determinantes psicológicos o situacionais do comportamento de conservaçào de àgua: um modelo estructural”. Estudos de Psicología. 8, 245-252.

Ídem (2003c), "Situational and personal determinants of waste control practices in Northern Mexico: a study of reuse and recycling behaviors”. Recourses, Conservation \& Recycling. 39,265-281.

Ídem (2006), “Psicología ambiental interamericana”. Medio Ambiente y Comportamiento Humano. 7 (1), 1-5.

Corral, V. y Encinas, L. (2001), "Variables disposicionales, situacionales y demográficas en el reciclaje de metal y papel”. Medio Ambiente y Comportamiento Humano. 2, 1-19.

Corral, V. y Frías, M. (2006), “Personal normative beliefs, antisocial 
behavior, and residential water conservation”. Environment and Behavior. 38, 406-421.

Corral, V. y Obregón, F. J. (1992), “Modelos predictores del comportamiento proambientalista”. Revista Sonorense de Psicología. 6, 5-14.

Corral, V. y Pinheiro, J. (1999), “Condicoes para o estudo do comportamento próambiental. Estudos de Psicología”. 4, 7-22.

Ídem (2004), “Aproximaciones al estudio de la conducta sustentable”. Medio Ambiente y Comportamiento Humano. 5 (1 y 2), 1-26.

Corral, V. y Zaragoza, F. (2000), “Bases sociodemográficas y psicológicas de la conducta de reutilización: Un Modelo estructural”. Medio Ambiente y Comportamiento Humano. 1, 9-29.

Corral, V., Bechtel, R., Armendáriz, L. I. y Esquer, A. B. (1997), “La estructura de las creencias ambientales en universitarios mexicanos: el Nuevo Paradigma Ambiental”. Revista Mexicana de Psicología. 14, 173-181.

Corral, V., Bonnes, G., Tapia, C., Fraijo, B., Frías, M. \& Carrus, G. (2009), "Correlates of pro-sustainability orientation: The affinity towards diversity". Journal of Environment Psychology. 29, 34-43

Corral, V., Carrus, G., Bonnes, M., Moser, G. \& Sinha, J. (2008), "Environment beliefs and endorsement of Sustainable Development principles in water conservation”. Environment and Behavior 40 (5), 703725

Corral, V., Fraijó, B. y Pinheiro, J. (2006), “Sustainable behavior and time perspective: present, past, and future orientations and their relationships with water conservation behavior”. Revista Interamericana de Psicología 40 (2), 139-147

Corral, V., Fraijó, B. Y Tapía, C. (2004), “Propensiones psicológicas en niños de sexto grado de primaria. Validez de un instrumento”. Anuario de Investigaciones Educativas. 7, 31-44

Corral, V., Frías, M. \& González, D. (2001), “On the relationship between antisocial and anti-environmental behaviors: an empirical study”. Population and Environment. 24, 273-286.

Ídem (2003), "Percepción de riesgos, conducta proambiental y variables demográficas en una comunidad de Sonora, México”. Región y Sociedad. 26, 49-72

Corral, V., Frías, M., Fraijo, B. y Tapia, C. (2006), “Rasgos de la conducta antisocial como correlatos del actuar anti y proambiental”. Medio Ambiente y Comportamiento Humano. 7 (1), 89-103 
Corral, V., Tapia, C., Fraijo, B. Mireles, J. y Marquez, P. (2008), “Orientación a la sustentabilidad como determinante de los estilos de vida sustentables. Un estudio con una muestra mexicana”. Revista Mexicana de Psicología. 25 (2) 313-327

Corral, V., Varela, C. y González, D. (2002), “Una taxonomía funcional de competencias proambientales”. La Psicología Social en México. 9, 592597.

Crano, W. \& Prislin, R. (2006), “Attitudes and persuasion”. Annual Review of Psychology. 57, 345-374.

Díaz, I. (2007), “El agua en el contexto de las ciudades sustentables”. En Morales, J. y L. Rodríguez (coord.). Economía del agua. Escasez del agua y su demanda doméstica e industrial en áreas urbanas. (pp. 335-349). México: Porrúa-UAM.

Dounlap, R. Y Van Liere, K. (1978), “The 'new Environmental Paradigm' ”. Journal of Environmental Education. 9, 10-19 .

Dovidio, J., Gaertner, S. \& Saguy, T. (2009), “Commonality and the complexity of us social attitudes and social change”. Personality and Social Psychology Review. 13, 3-20.

Espinosa, G., Orduña, V. y Corral, V. (2002), "Modelamiento estructural de las competencias proambientales para el ahorro de agua”. La Psicología Social en México. 9, 605-610.

Evans, G., Brauchle, G., Haq, A., Stecker, R., Wong, K. \& Shapiro, E. (2007), "Young children's environmental attitudes and behaviors". Environment \& Behavior. 39, 635-659.

Fazio, R. y Olson, M. (2003), "Implicit measures in social cognition research: their meaning and use”. Annual Review of Psychology. 54, 297327.

Feldman, J. \& Lynch, J. (1988), “Self-generated validity and other effects of measurement of belief, attitude, intention, and behavior”. Journal of Applied Psychology. 73, 421-435.

Fondo de las Naciones Unidas para la Infancia (2010), Pobreza infantil en países ricos. UNICEF, Nueva York.

Frías, M., Martín, A. y Corral, V. (2009), “Análisis de factores que influyen en el desarrollo de normas ambientales y en la conducta anti-ecológica”. Revista Interamericana de Psicología. 43 (2), 309-322.

Goicoechea, J. (2004), “Servicios domiciliarlos de agua y drenaje en México: cobertura relativa y convergencia”. En M. Villa y E. Saborio (coord.). 
La gestión del agua en México: los retos para el Desarrollo Sustentable. (pp. 111-132) México: Porrúa-UAM.

Ídem (2007), “Desempeño económico de la Península de Yucatán: agua potable y organismos operadores”. En Morales, J. y L. Rodríguez (coord.). Economía del agua. Escasez del agua y su demanda doméstica e industrial en áreas urbanas. (pp. 259-286). México: Porrúa-UAM.

González, A. y Amérigo, M. (1999), “Actitudes hacia el medio ambiente y conducta ecológica”. Psicothema. 11, 13-25.

González, M. (2007), “Hacia el desarrollo local en espacios rurales: el caso de Rincon Grande en Michoacan”. En Rosales, R. (coord.). Desarrollo Local: Teoría y practica socioterritoriales. (pp. 277-307). UAM-Porrúa, México.

Guering, B. (1994), “Attitudes and beliefs as verbal behavior”. Behavior Analyst. 17, 155-163.

Gutiérrez, R., Gómez, E., Jackson, M. y Manjarrez, O. (2000), “¿Cuál es el pensamiento social de los vecinos de la Purísima sobre el Medio Ambiente?”, La Psicología Social en México. 8, 353-359.

Harmon, E. (2007), “Cognitive Dissonance Theory after 50 years of development”. Zeitschrift fûr Sozialpsychologie. 38, 7-16.

Hernández, B., Corral, V., Hess, S. y Suárez, E. (2001), “Sistemas de creencias ambientales: un análisis multimuestra de estructuras factoriales”. Estudios de Psicología. 22, 53-64.

Hernández, F. (2004), “La administración del negocio del agua”. En M. Villa y E. Saborio (coord.). La gestión del agua en México: los retos para el Desarrollo Sustentable. (pp. 329-336) México: Porrúa-UAM.

Instituto Nacional de Estadística, Geografía e Informática (2010), XIII Censo Nacional de Población y Vivienda. INEGI, México.

Kallis, G., Ray, I., Fulton, J. \& McMahon J. (2010), “Public versus private: Does it matter for water conservation? Insights from California”. Environment Management. 45 (1), 177-191.

Kline, R. (1998), Principles and practice of structural equations modelling. Guilford Press, New York.

Ídem (2006), "Reverse arrow dynamics. Formative measurement and feedback loops”. In G. Hancock \& R. Mueller (coord.), Structural Equation Modeling: A Second Course. (pp. 43-68). Greenwood, CT: Information Age Publishing, Inc. 
Leiserowitz, A., Kates, R. \& Parris, T. (2006), “Sustainability values, attitudes and behaviors: a review of multinational and global trends". Annual Review of Environmental Resources. 31, 413-444.

López, M. (2004), “El programa de modernización del manejo del agua: avances y perspectivas”. En M. Villa y E. Saborio (coord.), La gestión del agua en México: los retos para el Desarrollo Sustentable. (pp. 103-110) México: Porrúa-UAM.

Marandu, E., Moeti, N. \& Haika, J. (2010), "Predicting residential water conservation using the Theory of Reasoned Action”, Journal of Communication. 1 (2), 87-100

March, H. \& Sauri, D. (2009), "What lies behind domestic water use? A review essay on the drivers of domestic water consumption”. AGEN. 50, 297-314

Martínez, J. (2004), “La estructura de la responsabilidad ambiental hacia la conservación de agua potable en jóvenes estudiantes”. Medio Ambiente y Comportamiento Humano. 5, 115-132

Martinportugues, C., Canto, J. y García, M. (2002), “Actitudes hacia el ahorro de agua: un análisis descriptivo”. Medio Ambiente y Comportamiento Humano. 3, 119-143

McFarie, B. \& Hunt, L. (2006), “Environmental activism in the forest sector. Social psychological, social cultural, and contextual effects”. Environment and Behavior. 38, 266-285

Medina, R. (2004), "Participación ciudadana en gestión del agua”. En M. A. Villa y E. Saborio (coord.). La gestión del agua en México: los retos para el Desarrollo Sustentable. (pp. 329-338) Universidad Autónoma Metropolitana, México.

Mercado, S. y López, E. (2004), “Estructura de la red semántica de los conceptos casa y hogar”. La Psicología Social en México. 10, 477-482

Milfont, T. \& Duckitt, J. (2004), “The structure of environmental attitudes: a firts and second cader confirmatory factor analisis”“. Journal of Environmental Psychology. 24, 289-303

Ídem (2006), Preservation and utilization the structure of environmental attitutes”. Medio Ambiente y Comportamiento Humano. 7, 29-50

Milfont, T. \& Gouveia, V. (2006), “Time perspective and values: an exploratory study of their relations to environmental attitudes”. Journal of Environmental Psychology. 26, 72-82

Mondéjar, J., Cordente, M., Meseguer, M. \& Gázquez, J. (2011), 
“Environmental Behavior and Water Saving in Spanish Housing”. International Journal Environment Research. 5 (1), 1-10

Montero, D. (2007), “Capitalismo, transnacionales y agua. La gran encrucijada del siglo XXI”. En A. Guillén (coord.). Economía y sociedad en América Latina: entre la globalización, la regionalización y el cambio estructural. (pp.289-317). Porrúa-Uam, México.

Ídem (2009), "El sistema de concesiones del agua en México y la participación de los grandes consorcios internacionales”. En D. Montero, Gómez, E., Carrillo, G. y Rodríguez, L. (coord.). Innovación tecnológica, cultura y gestión del agua. (pp. 93-118). Porrúa-Uam, México.

Obregón, F. y Zaragoza, F. (2000), “La relación de tradición y modernidad con las creencias ambientales”. Revista Sonorense de Psicología. 14, 6371.

Organización de las Naciones Unidas para la Agricultura y la Alimentación (2010), El estado de la inseguridad alimentaria en el mundo. FAO, Nueva York.

Organización de Naciones Unidas (2005), Agua para todos, agua para la vida. Informe sobre el desarrollo de recursos hídricos en el mundo. ONU, Nueva York.

Organización Mundial de la Salud (2010), Informe anual sobre pandemias. OMS, Ginebra.

Pato, C. y Tamayo, A. (2006), "Valores, creencias ambientales y comportamiento ecológico del activismo”, Medio Ambiente y Comportamiento Humano. 7 (1), 51-66.

Pato, C., Ross, M. y Tamayo, A. (2005), “Creencias y comportamiento ecológico: un estudio empírico con estudiantes brasileños”. Medio Ambiente y Comportamiento Humano. 6 (1), 5-22.

Pato, C., Tróccoli, B. \& Tamayo, A. (2002), Values and ecological behavior: an empirical study of Brazilians students. 17 ${ }^{\text {th }}$ Conference of IAPS 2002.

Petty, R. \& Cacioppo, J. (1986a), “The elaboration likelihood model of persuasion”. Advances in Experimental Psychology. 19, 123-183.

Ídem (1986b), Communication and persuasion: central peripheral routes to attitude change. Springer-Verlag, New York.

Postigo, W. (2008), “Sobre el derecho humano al agua”. Quórum. 16, 133150.

Risen, J. y Chen, K. (2010), “How to study choice-induced attitude change: 
strategies for fixing the free choice paradigm”. Social and Personality Psychology Compass. 4, 1151-1164.

Rodríguez, O., Melo, M., Sánchez, A., García, K. y Lázaro, D. (2002), “El agua: representaciones y creencias de ahorro y dispendio”. Polis. 1, 29-44.

Rucker, D. y Petty, R. (2006), “Increasing the effectiveness of communications to consumers: recommendations based on elaboration likelihood and attitude certainty perspectives”. Journal of Public Policy \& Marketing. 25, 39-52.

Rusell, S. \& Fielding, K. (2010), "Water demand management research: a psychological perspective”. Water Resources Research. 46, 1-12.

Sainz, J. y Becerra, M. (2003), “Los conflictos por agua en México: avances de investigación”. Gaceta del Instituto Nacional de Ecología. 67, 6168.

Santos, J. (2004), Acción pública organizada: el caso del servicio de agua potable en la zona conurbada de San Luis Potosí. UAM-Porrúa, México.

Schwartz, N. \& Bohner, G. (2001), “The construction of attitudes”. In A. Tesser \& Schwartz, N. (Ed.). Handbook of Social Psychology. (pp. 436457). Oxford: Blackwell.

Smith, J. R., \& Hogg, M. A. (2008), “Social identity and attitudes”. In W. Crano \& R. Prislin (Eds.), Attitudes and attitude change (pp. 337-360). New York: Psychology Press.

Soares, D. (2007), “Transferencia tecnológica y participación femenina: un gran reto para el desarrollo rural”. En Rosales, R. (coord.). Desarrollo Local: Teoría y practica socioterritoriales. (pp. 225-247). UAM-Porrúa, México.

Syme, G., Shao, Q., Po, M. \& Campbell, E. (2004), "Predicting and understanding home garden water use". Landscape and Urban Planning. 68, 121-128.

Tal, I., Hill, D., Figueredo, A., Frías, M. \& Corral, V. (2006), “An evolutionary approach to explaning water conservation behavior”. Medio Ambiente y Comportamiento Humano. 7, 7-27.

Thompson, S. C. \& Stoutmeyer, K. (1991), “Water use and commons dilemma: The effects of education that focuses on long-term consequences and individual action”. Environment and Behavior. 23, 314-333.

Valencia, J. (2004), “La planeación hidráulica en México”. En M. Villa y E. Saborio (coord.). La gestión del agua en México: los retos para el Desarrollo Sustentable. (pp. 81-102) UAM, México. 
Valenzuela, B., Corral, V., Quijada, A., Griego, T., Ocaña, D. y Contreras, C. (2004), "Predictores disposicionales del ahorro de agua: Austeridad, Altruismo y propensión al Futuro”. La Psicología Social en México. 10, 527-532.

Vozmediano, L. y San Juan, C. (2005), “Escala del nuevo paradigma ecológico; propiedades psicométricas con una muestra española obtenida a través de Internet”. Medio Ambiente y Comportamiento Humano. 6, 3749.

Wong, P. (2004), “Agua y desarrollo regional sustentable: una aproximación metodológica”. En M. A. Villa y E. Saborio (coord.). La gestión del agua en México: los retos para el Desarrollo Sustentable. (pp. 283-300) Universidad Autónoma Metropolitana, México.

Wood, W. (2000), “Attiude change: persuasion and social influence”. Annual Review of Psychology. 51, 539-570.

Zhao, R. \& Chen, S. (2008), "Fuzzy pricing for urban water resources: Model construction and application”. Journal of Environment Management. 8, 458-466.

Recibido: 02.06.2012

Aceptado: 09.01.2013 